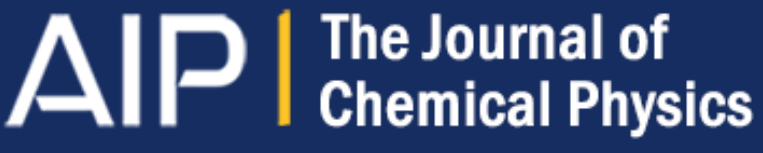

First principles-based multiparadigm, multiscale strategy for simulating complex materials processes with applications to amorphous SiC films

Saber Naserifar, William A. Goddard III, Theodore T. Tsotsis, and Muhammad Sahimi

Citation: The Journal of Chemical Physics 142, 174703 (2015); doi: 10.1063/1.4919797

View online: http://dx.doi.org/10.1063/1.4919797

View Table of Contents: http://scitation.aip.org/content/aip/journal/jcp/142/17?ver=pdfcov

Published by the AIP Publishing

\section{Articles you may be interested in}

Phase evolution and room-temperature photoluminescence in amorphous $\mathrm{SiC}$ alloy

J. Appl. Phys. 111, 103526 (2012); 10.1063/1.4721412

Aluminum induced in situ crystallization of amorphous SiC

Appl. Phys. Lett. 94, 181909 (2009); 10.1063/1.3132053

Crystallization of amorphous Si film by microwave annealing with $\mathrm{SiC}$ susceptors

Appl. Phys. Lett. 94, 102104 (2009); 10.1063/1.3097019

Structural characterization of annealed Si $1-x \mathrm{C}$ x / SiC multilayers targeting formation of Si nanocrystals in a SiC matrix

J. Appl. Phys. 103, 083544 (2008); 10.1063/1.2909913

First principles study of the initial stages of $\mathrm{SiC}$ growth on $\mathrm{Si}(001)$

Appl. Phys. Lett. 78, 2312 (2001); 10.1063/1.1366358

\section{How can you REACH $100 \%$}

of researchers at the Top 100

Physical Sciences Universities?

With The Journal of Chemical Physics.

AIP $\mid \begin{aligned} & \text { The Journal of } \\ & \text { Chemical Physics }\end{aligned}$

THERE'S POWER IN NUMBERS. Reach the world with AIP Publishing.

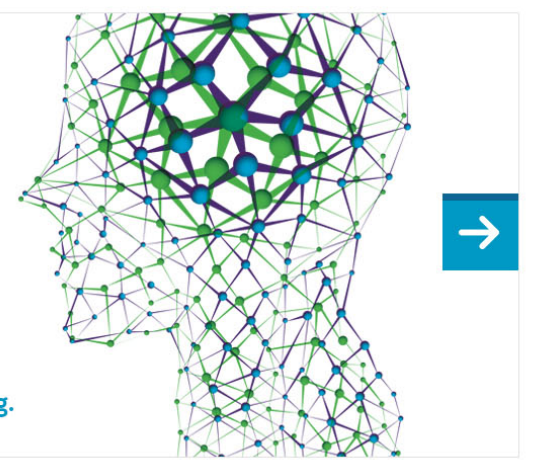




\title{
First principles-based multiparadigm, multiscale strategy for simulating complex materials processes with applications to amorphous SiC films
}

\author{
Saber Naserifar, ${ }^{1,2}$ William A. Goddard III, ${ }^{2}$ Theodore T. Tsotsis, ${ }^{1}$ \\ and Muhammad Sahimi ${ }^{1, a)}$ \\ ${ }^{1}$ Mork Family Department of Chemical Engineering and Materials Science, University of Southern California, \\ Los Angeles, California 90089-1211, USA \\ ${ }^{2}$ Materials and Process Simulation Center, California Institute of Technology, Pasadena, California 91125, USA
}

(Received 19 February 2015; accepted 23 April 2015; published online 6 May 2015)

\begin{abstract}
Progress has recently been made in developing reactive force fields to describe chemical reactions in systems too large for quantum mechanical (QM) methods. In particular, ReaxFF, a force field with parameters that are obtained solely from fitting QM reaction data, has been used to predict structures and properties of many materials. Important applications require, however, determination of the final structures produced by such complex processes as chemical vapor deposition, atomic layer deposition, and formation of ceramic films by pyrolysis of polymers. This requires the force field to properly describe the formation of other products of the process, in addition to yielding the final structure of the material. We describe a strategy for accomplishing this and present an example of its use for forming amorphous $\mathrm{SiC}$ films that have a wide variety of applications. Extensive reactive molecular dynamics (MD) simulations have been carried out to simulate the pyrolysis of hydridopolycarbosilane. The reaction products all agree with the experimental data. After removing the reaction products, the system is cooled down to room temperature at which it produces amorphous $\mathrm{SiC}$ film, for which the computed radial distribution function, x-ray diffraction pattern, and the equation of state describing the three main $\mathrm{SiC}$ polytypes agree with the data and with the QM calculations. Extensive MD simulations have also been carried out to compute other structural properties, as well the effective diffusivities of light gases in the amorphous SiC film. (C) 2015 AIP Publishing LLC. [http://dx.doi.org/10.1063/1.4919797]
\end{abstract}

\section{INTRODUCTION}

Many materials are fabricated by temperature-controlled thermal decomposition of polymers. They include porous amorphous carbon films, silicon carbide ( $\mathrm{SiC}$ ), silicon nitride, and aluminum nitride and have many important applications. ${ }^{1}$ $\mathrm{SiC}$, for example, ${ }^{2}$ has high fracture toughness and withstands high temperatures and has many applications, ranging from electronic devices and sensors, to structural materials, automobile parts, and thin filament pyrometry. Biocompatibility, resistance to acidic and alkali environments, and chemical inertness have also made $\mathrm{SiC}$ a promising material for fabrication of nanoporous membranes ${ }^{3}$ for separation of gas and liquid mixtures in harsh environments. $\mathrm{SiC}$ nanotubes are also being studied as storage medium for $\mathrm{H}_{2}$ and $\mathrm{CH}_{4}{ }^{4,5}$

A particular class of materials that is of interest to us in the present paper is amorphous $\mathrm{SiC}$ films, which are fabricated ${ }^{6}$ by pyrolysis of a partially allyl-substituted hydridopolycarbosilane (HPCS) and by chemical vapor deposition (CVD) using HPCS. Fundamental understanding of any phenomenon involving amorphous $\mathrm{SiC}$ (and similar materials) entails having an accurate atomistic model of the material. The most realistic route to developing such a model is one that mimics the process that produces $\mathrm{SiC}$ film. Since

\footnotetext{
a) Author to whom correspondence should be addressed. Electronic mail: moe@usc.edu
}

chemical reactions are also involved, the atomistic modeling requires reactive force fields (RFFs) that, in conjunction with molecular dynamics (MD) simulations, can mimic the actual processes.

To obtain a fundamental understanding of the pyrolysis process that leads to the formation of amorphous $\mathrm{SiC}$ film, we have carried out detailed atomistic simulations. But, because the size of the polymers used in the pyrolysis is large, modeling of the process using $a b$ initio methods is computationally prohibitive. Therefore, we have developed a RFF to match our extensive quantum mechanical $(\mathrm{QM})$ calculations, carried out with small systems, in order to estimate the parameters of the RFF. We then used the RFF to carry out reactive MD (RMD) simulation of the pyrolysis process. As reviewed by Farah et al. ${ }^{7}$ there are currently several RFFs that are capable of simulating reactive systems. Three of the better known of such methods and RFFs are as follows.

The RFF ReaxFF was developed by van Duin, Goddard, and coworkers, ${ }^{8}$ who used it to study the properties of a large number of reactions in metallic, ceramic, semiconductor, and polymeric materials. Another RFF is the reactive empirical bond-order potentials developed by Brenner and coworkers. ${ }^{9}$ They utilized their RFF to study carbon materials. Nyden and Noid ${ }^{10}$ used a conventional nonreactive FF but dynamically varied it in order to describe chemical reactions. Chemical reactions can also be simulated by the tight binding and density functional methods. The former requires prohibitive 
computations, if the atomistic size of the material to be simulated is to be large, while the latter has been used in parts of our computations, to be described below. The focus of the present paper is on RMD simulation of chemical reactions, using ReaxFF. Several empirical and semi-empirical FFs have, of course, been developed for amorphous $\mathrm{SiC},{ }^{11,12}$ but they are not capable of simulating chemical reactions.

Thus, in this paper, we describe a multiparadigm, multiscale strategy for simulating the pyrolysis of a polymer, with application to the formation of amorphous SiC films. We utilize ReaxFF in order to bridge the gap between the computational methods based on QM and empirical FFs. The QM methods are, in principle, applicable to all materials but, as already pointed out, their prohibitive computational requirement makes them unsuitable for large systems with more than a few hundred atoms. But, ReaxFF makes it possible to carry out RMD simulations of large-scale reactive chemical systems with accuracy comparable to that of the QM computations but at a fraction of the computational cost. One key feature of ReaxFF is that it describes accurately bond breaking and bond formation in materials, which is why we use it in the RMD simulation of pyrolysis of a polymer. There have been a number of studies for simulating pyrolysis and thermal degradation of polymers using ReaxFF. For example, Chenoweth et al. ${ }^{13}$ used ReaxFF to investigate the thermal decomposition of Poly(dimethylsiloxane). Desai et al. ${ }^{14}$ studied the pyrolysis of phenolic polymer in the presence of carbon nanotubes, while Saha and Schatz studied ${ }^{15}$ thermal decomposition of polyacrylonitrile in the carbonization process.

The rest of this paper is organized as follows. In Sec. II, we describe the essentials of ReaxFF. Section III explains the estimation of the parameters of ReaxFF using QM computations. In Sec. IV, we describe the RMD simulation of thermal decomposition of the HPCS, while Sec. V provides the details of the formation of amorphous SiC film by MD simulation. The results are presented and discussed in Sec. VI. The paper is summarized in Sec. VII.

\section{THE REACTIVE FORCE FIELD}

ReaxFF uses a general relationship between bond distance and bond order, on the one hand, and between bond order and bond energy, on the other hand, leading to proper dissociation of the bonds and atoms. The total energy $E$ of a system is given by

$$
\begin{aligned}
E= & E_{\text {bond }}+E_{\text {over }}+E_{\text {under }}+E_{\mathrm{val}}+E_{\text {con }}+E_{\text {tor }} \\
& +E_{\text {conj }}+E_{\mathrm{vdWaals}}+E_{\mathrm{ES}} .
\end{aligned}
$$

Here, $E_{\text {bond }}$ is the bond energy, $E_{\text {over }}$ accounts for a degree of over-coordination number that may remain in the material (e.g., the bond order of carbon cannot exceed 4 ), and $E_{\text {under }}$ is the energy due to the resonance of the $\pi$-electron between attached under-coordinated atoms. The valence angle energy is $E_{\mathrm{val}}, E_{\mathrm{con}}$ and $E_{\text {conj }}$ are, respectively, the three- and fourbody conjugation energies, and $E_{\mathrm{tors}}$ is the torsional rotational barriers energy. Finally, $E_{\mathrm{ES}}$ represents the energy due to electrostatic interactions.
The expression for each partial energy is parameterized by a number of parameters. Their parameterized functional forms are long and given elsewhere ${ }^{8}$ and, thus, are not repeated here. The overall number of parameters for the HPCS is 438 , of which 39 are general, 50 are computed specifically by us for the HPCS, while the remaining 349 parameters are those computed previously by van Duin, Dasgupta et al. ${ }^{8}$ for Poly(dimethylsiloxane). Since we have three types of atoms in the HPCS, namely, Si, C, and H, then, there are 26 combinations of torsional angles. The torsion energy, however, contributes weakly to ReaxFF and, thus, only 9 terms out of 26 are used in the development of ReaxFF for HPCS.

\section{ESTIMATION OF THE PARAMETERS}

The parameters of ReaxFF are estimated so as to reproduce the first-principles QM interactions in the HPCS, by adding the SiC crystal chemistry and the QM data for systems relevant to the HPCS to the ReaxFF training set for $\mathrm{Si}$ materials, as described by van Duin, Strachan et al. ${ }^{8}$ The QM data for the nonperiodic systems were computed by the density-functional theory (DFT) using Jaguar (version 5.5), ${ }^{16}$ B3LYP (Becke three-parameter Lee-Yang-Parr) functional ${ }^{17}$ and Pople's 6-311G ${ }^{* *}$ basis set. ${ }^{18}$ The Mulliken charges were also computed using the same basis set. ${ }^{19}$ The unit cells used for each $\mathrm{SiC}$ polytopes and, therefore, the size of the systems varied from 8 to 16 atoms. For the energy and force convergence, the convergence criteria of $10^{-6} \mathrm{eV}$ and $10^{-4} \mathrm{eV} / \AA$ were used, respectively. The $k$-points were the Gamma point centered in the unit cells, and the symmetry of space groups was used. The equation of state for the $\beta$-SiC crystal structure was obtained by the DFT calculations using Quantum Espresso. ${ }^{20}$ The generalized gradient approximation $^{21}$ was used for the exchange-correlation energy, and ultrasoft pseudopotentials were utilized to replace the core electrons $^{22}$ with a kinetic energy cutoff of $320 \mathrm{eV}$. The Monkhorst-Pack scheme ${ }^{23}$ was used to generate the $k$-space grid with a spacing of $0.1 \AA^{-1}$.

The geometries and energies of the species and complexes in the HPCS were computed by the DFT, as were the products of the reactions. The $\mathrm{Si}-\mathrm{C}$ bond energy was optimized using the dissociation pathway for the $\mathrm{Si}-\mathrm{C}$ bond in $\mathrm{H}_{3} \mathrm{Si}-\mathrm{CH}_{3}$ and for $\mathrm{Si}=\mathrm{C}$ in $\mathrm{H}_{2} \mathrm{Si}=\mathrm{CH}_{2}$. The ReaxFF parameters were computed and optimized ${ }^{24}$ so as to minimize the differences between the energies calculated by DFT and ReaxFF. To do so, the DFT results for the singlets were used around the equilibrium bond distances. The valence angle parameters were optimized to represent the angle-changing energies, obtained from the DFT calculations for various clusters of atoms. Six valence angles in HPCS need to be accounted for, namely, $\mathrm{Si}-\mathrm{C}-\mathrm{Si}, \mathrm{Si}-\mathrm{C}-\mathrm{H}, \mathrm{C}-\mathrm{Si}-\mathrm{H}$, $\mathrm{C}-\mathrm{C}-\mathrm{Si}, \mathrm{C}-\mathrm{Si}-\mathrm{C}$, and $\mathrm{C}-\mathrm{Si}-\mathrm{Si}$. As their representative molecules, we used the triplets $\mathrm{H}_{3} \mathrm{Si}-\mathrm{CH}_{2}-\mathrm{SiH}_{3}$ for the first three and $\mathrm{H}_{3} \mathrm{C}-\mathrm{CH}_{2}-\mathrm{SiH}_{3}, \mathrm{H}_{3} \mathrm{C}-\mathrm{SiH}_{2}-\mathrm{CH}_{3}$, and $\mathrm{H}_{3} \mathrm{Si}-\mathrm{SiH}_{2}-\mathrm{CH}_{3}$ for, respectively, the last three. For each angle, the representative molecule's geometry was optimized with the angles of interest fixed, so as to compute the angle-changing energies (between three atoms) relative to the optimal geometry. 
The accuracy of the results is typically similar to or better than that provided by the parameterized model number 3 (the PM3 method), ${ }^{25}$ which is a semi-empirical method for QM computation of the electronic structure of molecules. ReaxFF is about 100 times faster than PM3, which in turn is about 100 times faster than the QM calculations.

\section{SIMULATION OF PYROLISIS OF THE POLYMER}

The next step is RMD simulation of thermal decomposition of the HPCS that, when followed by cooling the system back to room temperature, produces amorphous $\mathrm{SiC}$ film. Thus, we first generated an atomistic model of the HPCS by using a modified version of the self-avoiding walk (SAW) method of Theodorou and Suter ${ }^{26,27}$ to generate its initial structure. Three connected atoms of the HPCS' backbone were placed in random orientations in a cubic simulation cell. The HPCS was then constructed by adding one atom at a time using the modified SAW algorithm. The allowed rotational states of the successive bonds between adjacent atoms were determined from the probability distribution functions that were governed by energy considerations (see below). Periodic boundary conditions were used. The polymer-consistent force field (PCFF) was utilized to generate the molecular model of the HPCS. According to the PCFF, the total potential energy $E$ of the polymer is given by

$$
E=E_{s}+E_{\theta}+E_{\phi}+E_{\text {non-bond }}
$$

with

$$
\begin{gathered}
E_{S}=\sum_{i=1}^{4} K_{i}\left(l-l_{0}\right)^{i}, E_{\theta}=\sum_{i=2}^{4} H_{i}\left(\theta-\theta_{i}\right)^{i}, \\
E_{\phi}=\sum_{i=1}^{3} D_{i}(1-\cos i \phi),
\end{gathered}
$$

and

$E_{\text {non-bond }}=\sum_{i, j} \frac{q_{i} q_{j}}{r_{i j}}+\sum_{i j} \epsilon_{i j}\left[2\left(\frac{\sigma_{i j}}{r_{i j}}\right)^{9}-3\left(\frac{\sigma_{i j}}{r_{i j}}\right)^{6}\right]$.

Here, $E_{s}$ is the bond-stretching energy, with $l_{0}$ being a bond's equilibrium length, $l$ being its actual length at any time during the simulations, and $K_{i}$ being a stretching-force constant. $E_{\theta}$ represents the energy associated with the changes in the bonds' angles, where $\theta_{0}$ is the equilibrium angle of a bond, $\theta$ is its angle during the simulation, and $H_{i}$ is the corresponding force constant. The contribution of the torsional forces is represented by $E_{\phi}$, with $D_{i}$ being a force constant and $\phi_{i}$ being the dihedral angle. The parameters $\sigma_{i}$ and $\epsilon_{i}$ are, respectively, the LennardJones (LJ) size and energy parameters for atom $i$ and $q_{i}$ is the partial charge of $i$. The nonbond interactions were cut off at an interatomic distance of $12.5 \AA$, while a spline switching function was used between 9.5 and $12.5 \AA$. The cutoffs were selected carefully, based on extensive preliminary simulations, as well as our previous extensive experience with modeling of electrostatic interactions using the multipole expansion ${ }^{28}$ and the Ewald summation ${ }^{29}$ techniques. One may, of course, use other methods of calculating the electrostatic interactions. ${ }^{30}$ While including corrections due to the introduction of the cutoffs would make the simulations somewhat more accurate, for the main purpose of the present work, namely, creating an initial atomistic model of the HPCS to be used with ReaxFF for modeling its pyrolysis, the cutoffs without any corrections seemed to suffice. All the parameters of the PCFF are given elsewhere ${ }^{27}$ and need not be repeated here.

Energy minimization and MD simulations were utilized in order to generate the equilibrated atomistic model of the polymer. The density of the polymer at the beginning of the
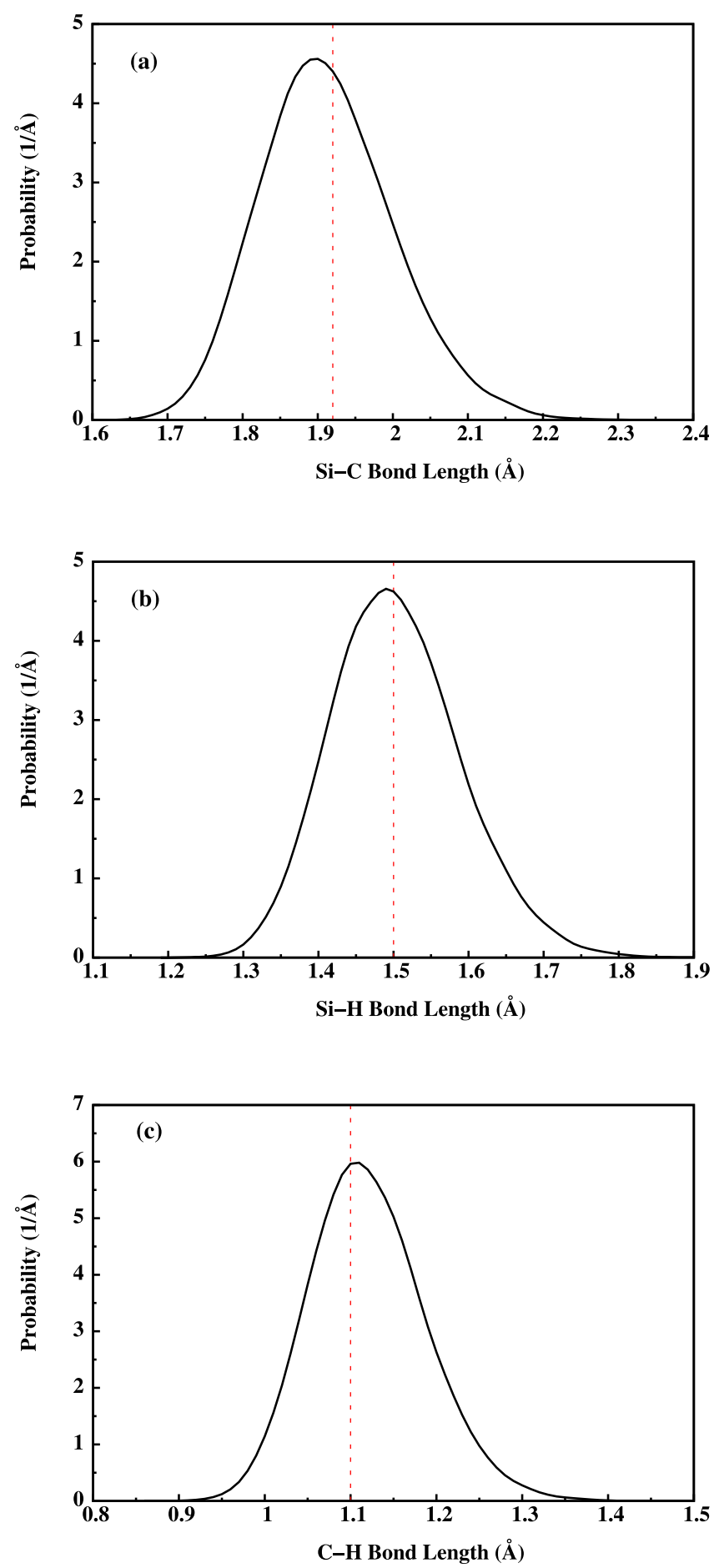

FIG. 1. The distributions of the bond length in (a) $\mathrm{Si}-\mathrm{C}$, (b) $\mathrm{Si}-\mathrm{H}$, and (c) $\mathrm{C}-\mathrm{H}$ in the HPCS polymer, as generated by the PCFF. The vertical dashed lines show location of the reference bond lengths. 
energy minimization was set at $0.15 \mathrm{~g} / \mathrm{cm}^{3}$, so as to avoid ring spearings and catenations. The total energy $E$ of the polymer was then minimized using the conjugate-gradient method. The equilibrated structure was then compressed using MD simulation in the (NPT) ensemble at pressures between 0.5 and $0.6 \mathrm{GPa}$, in order to increase the polymer density to be as close to the experimental value of $0.98 \mathrm{~g} / \mathrm{cm}^{3}$ as possible. This was followed by energy minimization and short-duration MD simulations in the $(N V T)$ ensemble at $1000 \mathrm{~K}$, in order to further relax the material. Then, MD simulations were carried out in the (NPT) ensemble for several ns at $1 \mathrm{~atm}$ and $300 \mathrm{~K}$. The time step was always $1 \mathrm{fs}$. The pressure was controlled by the Andersen method, ${ }^{31}$ for which we used $W=20 \mathrm{amu}$ for the barostat's masslike parameter. The temperature was held fixed using the Nosé-Hoover thermostat ${ }^{32}$ for which the parameter to scale the fictitious mass was set at 1 .

To demonstrate that the PCFF generates the correct polymer structure, we show in Fig. 1 the distributions of $\mathrm{Si}-\mathrm{C}$, $\mathrm{S}-\mathrm{H}$, and $\mathrm{C}-\mathrm{H}$ distances. Their maxima, corresponding to the most probable values, agree with the experimental data for the three bonds. For example, the length of the $\mathrm{Si}-\mathrm{C}$ bond is $1.9 \AA$, in agreement with what is known experimentally. Similarly, Figs. 2 and 3 present, respectively, the distributions of the triplet angles- $\mathrm{Si}-\mathrm{C}-\mathrm{Si}, \mathrm{Si}-\mathrm{C}-\mathrm{H}, \mathrm{C}-\mathrm{Si}-\mathrm{H}$, and $\mathrm{C}-\mathrm{Si}-\mathrm{C}-$ and the dihedral angles $-\mathrm{H}-\mathrm{C}-\mathrm{Si}-\mathrm{C}$, $\mathrm{H}-\mathrm{Si}-\mathrm{C}-\mathrm{Si}, \mathrm{H}-\mathrm{C}-\mathrm{Si}-\mathrm{H}$, and $\mathrm{Si}-\mathrm{C}-\mathrm{Si}-\mathrm{C}-$ in the HPCS, and the most probable values all agree with theoretical estimates. Thus, the PCFF is capable of producing the correct molecular structure for HPCS.

The atomistic model of the HPCS was then used with ReaxFF in the RMD simulation of its thermal decomposition. The simulations were carried out in the (NVT) ensemble. The heating rate was $0.1 \mathrm{~K} / \mathrm{fs}$. The temperature $T$ was gradually increased from $50 \mathrm{~K}$ to $5000 \mathrm{~K}$. For $T<1000 \mathrm{~K}$, the $\mathrm{Si}-\mathrm{H}$ and $\mathrm{C}-\mathrm{H}$ bonds are highly mobile and continuously form and break before the polymer begins to decompose. The RMD simulations indicated that the degradation of the polymer commences close to $1000 \mathrm{~K}$. Since the $\mathrm{Si}-\mathrm{H}$ bond is weaker than the $\mathrm{C}-\mathrm{H}$ bond by about $20 \mathrm{kcal} / \mathrm{mol}$, its cleavage initiated the decomposition process, consistent with the experimental data. ${ }^{33}$ For $T>1000 \mathrm{~K}$, extensive homolytic $\mathrm{Si}-\mathrm{H}$ and $\mathrm{C}-\mathrm{H}$ bond breaking occurred, releasing a large number of $\mathrm{H}$ radicals that formed bond between themselves and produced $\mathrm{H}_{2}$ gas, the pyrolysis' primary product. $\mathrm{SiH}_{n}$ (with $n=1$ and 2) also released $\mathrm{H}$, leading to the formation of reactive silylene (=Si:) intermediates and eventually the $\mathrm{Si}-\mathrm{Si}$ bonds. But, such bonds broke above $1000 \mathrm{~K}$ because Si tends to form more stable bonds with $\mathrm{C}$.

Cleavage of the $\mathrm{Si}-\mathrm{C}$ bonds began at about $2000 \mathrm{~K}$ and accelerated at $2400 \mathrm{~K}$ and higher. As a result, $\mathrm{CH}_{2}, \mathrm{SiH}_{2}$, and $\mathrm{CH}_{4} \mathrm{Si}$ radicals formed, which then reacted with the $\mathrm{H}$ radicals to form $\mathrm{CH}_{3}, \mathrm{SiH}_{3}$, and $\mathrm{CH}_{5} \mathrm{Si}$ radicals, and eventually methane, silane, and methylsilane gases. Other decomposition and reaction products included various $\mathrm{C}_{2}$ hydrocarbons
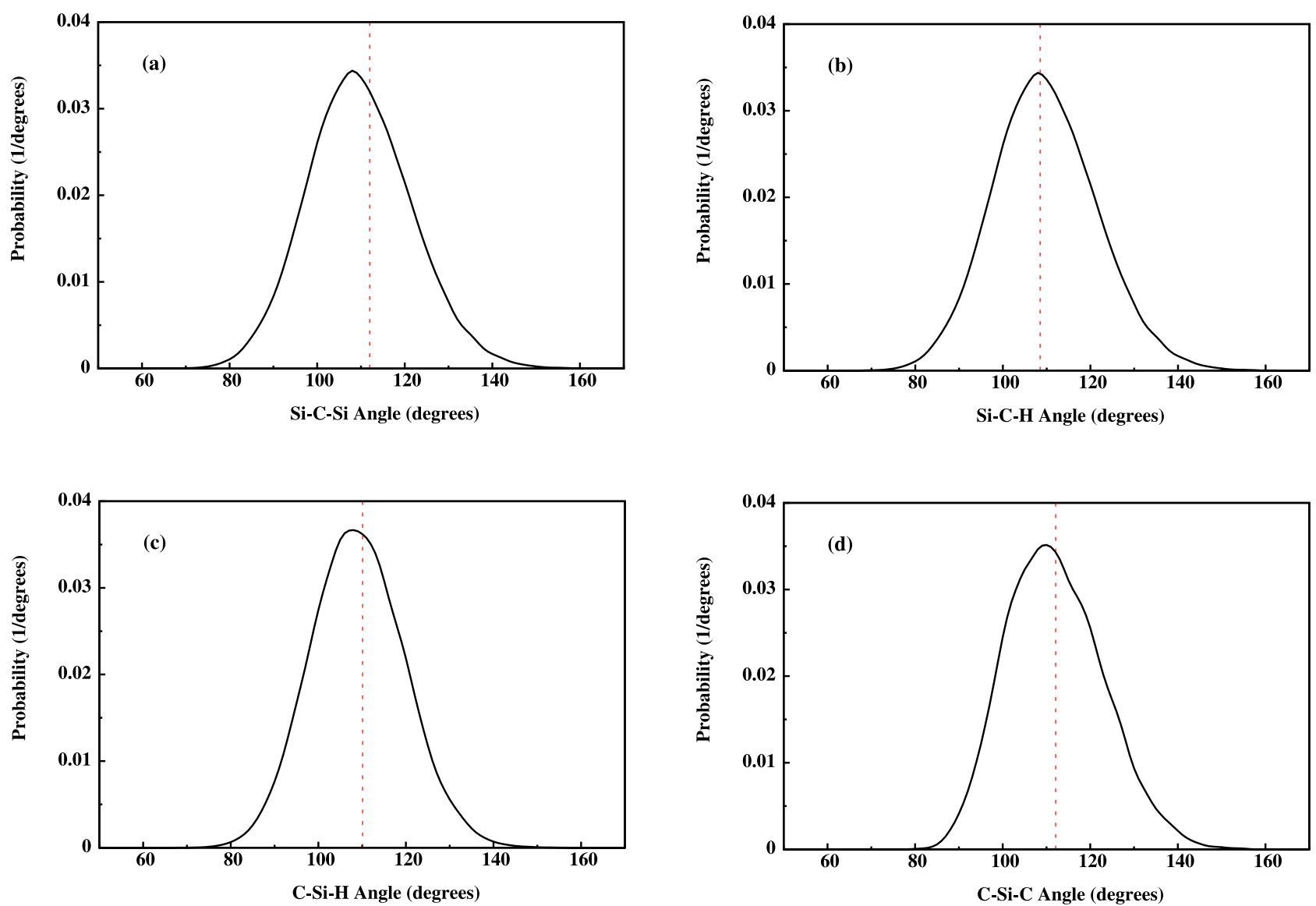

FIG. 2. The distributions of the angles in (a) $\mathrm{Si}-\mathrm{C}-\mathrm{Si}$, (b) $\mathrm{Si}-\mathrm{C}-\mathrm{H}$, (c) $\mathrm{C}-\mathrm{Si}-\mathrm{H}$, and (d) $\mathrm{C}-\mathrm{Si}-\mathrm{C}$ in the HPCS polymer, as generated by the PCFF. The vertical dashed lines show location of the reference angle values. 

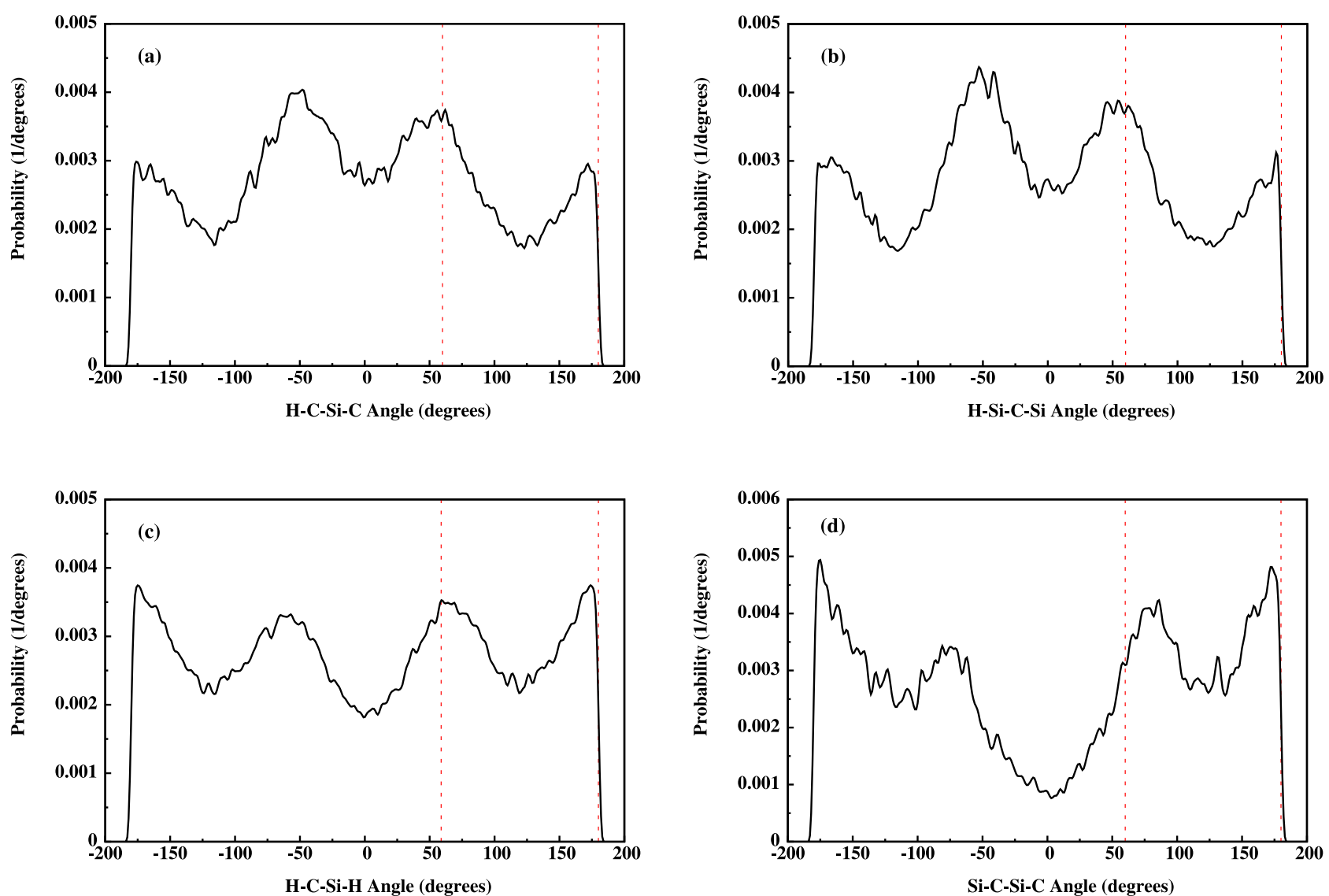

FIG. 3. The distributions of dihedral angles in (a) $\mathrm{H}-\mathrm{C}-\mathrm{Si}-\mathrm{C}$, (b) $\mathrm{H}-\mathrm{Si}-\mathrm{C}-\mathrm{Si}$, (c) $\mathrm{H}-\mathrm{C}-\mathrm{Si}-\mathrm{H}$, and (d) $\mathrm{Si}-\mathrm{C}-\mathrm{Si}-\mathrm{C}$ in the $\mathrm{HPCS}$ polymer, as generated by the PCFF. The vertical dashed lines show location of the reference dihedral angle values.

$\left(\mathrm{C}_{2} \mathrm{H}_{6}\right.$ and $\left.\mathrm{C}_{2} \mathrm{H}_{4}\right)$ and such radicals as $\mathrm{C}_{2} \mathrm{H}_{5}$ and $\mathrm{C}_{2} \mathrm{H}_{3}$, as well as $\mathrm{C}_{2} \mathrm{H}_{2}$.

\section{FORMATION OF THE SIC AMORPHOUS FILM}

Once the polymer was completely decomposed, formation of amorphous $\mathrm{SiC}$ was simulated by MD simulation. An important point must, however, be emphasized here. Clearly, the MD simulation can be carried for at most many nanoseconds, much shorter than the actual pyrolysis experiments that last several hours. At the same time, to capture all the changes in the geometries and charges and large variations in the density and atom connectivity, one must use short time steps; we used 0.1 fs. Therefore, the RMD simulation must be carried out at high enough temperatures in order to accelerate the computations, so that the chemical reactions can occur on the computational time scale.

\section{A. Simulation at high temperature}

Experiments ${ }^{34}$ indicate that for $T<1175 \mathrm{~K}$, the pyrolysis process produces amorphous $\mathrm{SiC}$ in which $\mathrm{Si}-\mathrm{H}$ and $\mathrm{C}-\mathrm{H}$ bonds break readily, releasing hydrogen radicals that eventually produce $\mathrm{H}_{2}$, but ${ }^{35}$ breaking of the $\mathrm{Si}-\mathrm{C}$ bonds is very limited. In fact, our RMD simulation indicated that for $T<2400 \mathrm{~K}$ the $\mathrm{Si}-\mathrm{C}$ bonds remain unbroken. Thus, simulation temperatures of $2400 \mathrm{~K}$ and lower are, roughly speaking, equivalent to the experimental temperatures of $1175 \mathrm{~K}$ and lower.

The reason is that experiments ${ }^{33}$ indicated that $\mathrm{H}_{2}$ is the major product of the pyrolysis, which is also what our RMD simulation produces. Due to being in a high energy state, free $\mathrm{H}$ radicals have a strong tendency to form $\mathrm{H}-\mathrm{H}$ bonds. This means that if we could carry out the RMD simulations over the experimental time scales, all the $\mathrm{H}$ radicals would eventually react and form $\mathrm{H}_{2}$. In the actual experiments, this takes on the order of several minutes to a few hours. Clearly, RMD simulations over such long time scales are not possible. Thus, by raising the temperature, we accelerate the formation of free $\mathrm{H}$ radicals and eventually $\mathrm{H}_{2}$ molecules over the computational time scales that are currently feasible to simulate. Based on such considerations and preliminary RMD simulations, we carried out the bulk of our MD simulations in the $(N V T)$ ensemble at $2000 \mathrm{~K}$.

\section{B. Incorporating insight from chemistry into the simulation}

Similar to the experiments, all the gaseous products of the pyrolysis must be deleted from the simulation cell as well, but this must be done carefully. Experiments ${ }^{34}$ indicated that $\mathrm{H}_{2}$ is the major product of the pyrolysis, which is also what our RMD simulation produces. Thus, to speed up the computations, every two $\mathrm{H}$ atoms may be viewed as being equivalent to one $\mathrm{H}_{2}$. In that case, deleting every two $\mathrm{H}$ radicals 
during the RMD simulation would be equivalent with deleting one $\mathrm{H}_{2}$ gas. Thus, we used shell programming to integrate the computer program with the GRASP package, in order to automatically delete the $\mathrm{H}$ radicals at $2-5$ ps intervals. The external program evaluated the distance of every $\mathrm{H}$ atom in the system from all the neighboring atoms- $\mathrm{C}, \mathrm{H}$, and $\mathrm{Si}-$ and if it exceeded the equilibrium bond length between $\mathrm{H}$ and the corresponding neighboring atom by a factor of 1.2 , it considered the $\mathrm{H}$ atom to be unbounded and deleted it from the simulation cell.

An important point must be emphasized here. One must be very careful about $\mathrm{H}$ removal and its effect on the dynamics of the system throughout the simulations. This is particularly important when the MD simulations are carried out within an ensemble in which the total number of atoms $(\mathrm{N})$ is held fixed. Here, the $\mathrm{H}$ radicals are produced gradually during the simulations, and the number of $\mathrm{H}$ atoms that are removed at appropriate times is, relative to the total number of the atoms, negligible. Thus, after each removal step, the system has enough time to readjust the potential and kinetic energies and, therefore, gradual removal of the $\mathrm{H}$ atoms does not negatively affect the dynamics of the system that was tracked carefully throughout the simulations.

After removing all the hydrogen atoms at $2000 \mathrm{~K}$, the system consisted of only $\mathrm{Si}$ and $\mathrm{C}$ atoms, which was then relaxed by MD simulation in the $(N V T)$ ensemble using the GRASP at $2000 \mathrm{~K}$ for a sufficient time to allow for rearrangement of the atoms and cross-linking between $\mathrm{Si}$ and $\mathrm{C}$ atoms. Thus, the $\mathrm{Si}$ and $\mathrm{C}$ atoms began to bond together, with $\mathrm{Si}-\mathrm{C}$ rings appearing in the structure. The potential energy of the system remained unchanged after 820 ps, implying that the system had reached its true equilibrium state. Experimentally, ${ }^{36}$ the amorphous $\mathrm{SiC}$ produced at $1025 \mathrm{~K}$ is nearly stoichiometric with a density of $2.2 \mathrm{~g} / \mathrm{cm}^{3}$, containing a small percentage of hydrogen. Thus, the simulation cell was compressed to achieve the density of the amorphous $\mathrm{SiC}$ ceramic, using (NPT)-MD simulation at $2000 \mathrm{~K}$. Thereafter, it was cooled down to ambient $T$ with a cooling rate of $0.1 \mathrm{~K} / \mathrm{fs}$ and equilibrated further to release the extra pressure and achieve equilibrium using (NPT)-MD simulations. Finally, simulated annealing in the $(N V T)$ ensemble was utilized to surmount the energetic barriers, in a search for conformations with energies lower than the possibly local-minimum energy identified previously.

\section{RESULTS AND DISCUSSION}

In what follows, we present and discuss the results, first for the reaction products of HPCS pyrolysis and then for the amorphous $\mathrm{SiC}$ films that the MD simulation generated.

\section{A. Reaction products}

All the computed parameters of ReaxFF are given elsewhere. ${ }^{37}$ In Table I, we list all the reaction products generated by the RMD simulations. These are in agreement with the experimental data, ${ }^{33}$ both qualitatively and quantitatively, for the products of the HPCS decomposition. Reference 33 reported, for example, that most of the produced gas was
TABLE I. The pyrolysis products after heating up the polymer to $3600 \mathrm{~K}$. $N$ is the number of the produced product, and MW its molecular weight.

\begin{tabular}{|c|c|c|c|c|c|}
\hline$N$ & Product & MW & $N$ & Product & MW \\
\hline 122 & $\mathrm{H}$ & 1.00 & 1 & $\mathrm{C}_{2} \mathrm{H}_{5} \mathrm{Si}_{3}$ & 113.32 \\
\hline 26 & $\mathrm{H}_{2}$ & 2.00 & 1 & $\mathrm{C}_{2} \mathrm{H}_{7} \mathrm{Si}_{3}$ & 115.33 \\
\hline 3 & $\mathrm{CH}_{3}$ & 15.03 & 3 & $\mathrm{C}_{2} \mathrm{H}_{10} \mathrm{Si}_{3}$ & 118.36 \\
\hline 11 & $\mathrm{CH}_{4}$ & 16.04 & 1 & $\mathrm{C}_{2} \mathrm{H}_{11} \mathrm{Si}_{3}$ & 119.36 \\
\hline 2 & $\mathrm{C}_{2} \mathrm{H}_{4}$ & 28.05 & 1 & $\mathrm{C}_{5} \mathrm{H}_{9} \mathrm{Si}_{2}$ & 125.29 \\
\hline 3 & $\mathrm{HSi}$ & 29.09 & 3 & $\mathrm{C}_{3} \mathrm{H}_{8} \mathrm{Si}_{3}$ & 128.35 \\
\hline 7 & $\mathrm{H}_{2} \mathrm{Si}$ & 30.10 & 1 & $\mathrm{C}_{3} \mathrm{H}_{9} \mathrm{Si}_{3}$ & 129.36 \\
\hline 5 & $\mathrm{H}_{3} \mathrm{Si}$ & 31.11 & 2 & $\mathrm{C}_{3} \mathrm{H}_{10} \mathrm{Si}_{3}$ & 130.37 \\
\hline 10 & $\mathrm{H}_{4} \mathrm{Si}$ & 32.12 & 1 & $\mathrm{C}_{4} \mathrm{H}_{12} \mathrm{Si}_{3}$ & 144.39 \\
\hline 1 & $\mathrm{CSi}$ & 40.09 & 1 & $\mathrm{C}_{4} \mathrm{H}_{13} \mathrm{Si}_{3}$ & 145.40 \\
\hline 4 & $\mathrm{CH}_{2} \mathrm{Si}$ & 42.11 & 1 & $\mathrm{C}_{2} \mathrm{H}_{12} \mathrm{Si}_{4}$ & 148.46 \\
\hline 14 & $\mathrm{CH}_{3} \mathrm{Si}$ & 43.12 & 1 & $\mathrm{C}_{3} \mathrm{H}_{10} \mathrm{Si}_{4}$ & 158.45 \\
\hline 16 & $\mathrm{CH}_{4} \mathrm{Si}$ & 44.13 & 1 & $\mathrm{C}_{3} \mathrm{H}_{11} \mathrm{Si}_{4}$ & 159.46 \\
\hline 10 & $\mathrm{CH}_{5} \mathrm{Si}$ & 45.13 & 1 & $\mathrm{C}_{4} \mathrm{H}_{12} \mathrm{Si}_{4}$ & 172.48 \\
\hline 5 & $\mathrm{CH}_{6} \mathrm{Si}$ & 46.14 & 1 & $\mathrm{C}_{4} \mathrm{H}_{13} \mathrm{Si}_{4}$ & 173.49 \\
\hline 1 & $\mathrm{CH}_{7} \mathrm{Si}$ & 47.15 & 1 & $\mathrm{C}_{5} \mathrm{H}_{14} \mathrm{Si}_{4}$ & 186.50 \\
\hline 1 & $\mathrm{C}_{2} \mathrm{H}_{2} \mathrm{Si}$ & 54.12 & 1 & $\mathrm{C}_{3} \mathrm{H}_{15} \mathrm{Si}_{5}$ & 191.58 \\
\hline 1 & $\mathrm{C}_{2} \mathrm{H}_{3} \mathrm{Si}$ & 55.13 & 1 & $\mathrm{C}_{4} \mathrm{H}_{13} \mathrm{Si}_{5}$ & 201.57 \\
\hline 3 & $\mathrm{C}_{2} \mathrm{H}_{5} \mathrm{Si}$ & 57.14 & 1 & $\mathrm{C}_{4} \mathrm{H}_{14} \mathrm{Si}_{5}$ & 202.58 \\
\hline 3 & $\mathrm{C}_{2} \mathrm{H}_{6} \mathrm{Si}$ & 58.15 & 1 & $\mathrm{C}_{4} \mathrm{H}_{15} \mathrm{Si}_{5}$ & 203.59 \\
\hline 1 & $\mathrm{C}_{2} \mathrm{H}_{7} \mathrm{Si}$ & 59.16 & 1 & $\mathrm{C}_{5} \mathrm{H}_{15} \mathrm{Si}_{5}$ & 215.60 \\
\hline 1 & $\mathrm{CH}_{4} \mathrm{Si}_{2}$ & 72.21 & 1 & $\mathrm{C}_{5} \mathrm{H}_{19} \mathrm{Si}_{5}$ & 219.63 \\
\hline 2 & $\mathrm{CH}_{5} \mathrm{Si}_{2}$ & 73.22 & 1 & $\mathrm{C}_{6} \mathrm{H}_{16} \mathrm{Si}_{5}$ & 228.62 \\
\hline 4 & $\mathrm{CH}_{6} \mathrm{Si}_{2}$ & 74.23 & 2 & $\mathrm{C}_{7} \mathrm{H}_{16} \mathrm{Si}_{5}$ & 240.63 \\
\hline 1 & $\mathrm{CH}_{7} \mathrm{Si}_{2}$ & 75.24 & 1 & $\mathrm{C}_{5} \mathrm{H}_{15} \mathrm{Si}_{6}$ & 243.69 \\
\hline 3 & $\mathrm{C}_{2} \mathrm{H}_{5} \mathrm{Si}_{2}$ & 85.23 & 1 & $\mathrm{C}_{6} \mathrm{H}_{19} \mathrm{Si}_{6}$ & 259.73 \\
\hline 3 & $\mathrm{C}_{2} \mathrm{H}_{6} \mathrm{Si}_{2}$ & 86.24 & 1 & $\mathrm{C}_{6} \mathrm{H}_{19} \mathrm{Si}_{7}$ & 287.81 \\
\hline 4 & $\mathrm{C}_{2} \mathrm{H}_{7} \mathrm{Si}_{2}$ & 87.25 & 1 & $\mathrm{C}_{8} \mathrm{H}_{25} \mathrm{Si}_{7}$ & 317.88 \\
\hline 1 & $\mathrm{C}_{2} \mathrm{H}_{8} \mathrm{Si}_{2}$ & 88.25 & 1 & $\mathrm{C}_{9} \mathrm{H}_{20} \mathrm{Si}_{8}$ & 352.94 \\
\hline 2 & $\mathrm{C}_{2} \mathrm{H}_{9} \mathrm{Si}_{2}$ & 89.26 & 1 & $\mathrm{C}_{14} \mathrm{H}_{37} \mathrm{Si}_{12}$ & 542.47 \\
\hline 1 & $\mathrm{C}_{2} \mathrm{H}_{10} \mathrm{Si}_{2}$ & 90.27 & 1 & $\mathrm{C}_{14} \mathrm{H}_{39} \mathrm{Si}_{13}$ & 572.57 \\
\hline 1 & $\mathrm{C}_{3} \mathrm{H}_{8} \mathrm{Si}_{2}$ & 100.27 & 1 & $\mathrm{C}_{17} \mathrm{H}_{42} \mathrm{Si}_{13}$ & 611.63 \\
\hline 2 & $\mathrm{C}_{3} \mathrm{H}_{9} \mathrm{Si}_{2}$ & 101.27 & & & \\
\hline
\end{tabular}

hydrogen, followed in much smaller quantities by $\mathrm{CH}_{4}$, $\mathrm{SiH}_{4}$, and other low-molecular weight gases. These are also what we obtained, as well as other gases that may not be possible to measure experimentally with any precision due to their trace amount. This is, of course, an advantage of ReaxFF. Previously, we also compared ${ }^{37}$ the results of the QM calculations with those obtained with ReaxFF, and the two agree closely.

Figure 4 presents the "pie chart" for all the radicals and molecules produced at $3600 \mathrm{~K}$. Consistent with experiments, hydrogen radicals constitute the major component of the reaction products, hence explaining why $\mathrm{H}_{2}$ is the most important product of the pyrolysis. This is followed by $\mathrm{C}_{n} \mathrm{H}_{p} \mathrm{Si}_{m}$ that eventually produce $\mathrm{CH}_{4}$ and $\mathrm{SiH}_{4}$ and trace amounts of other gaseous compounds. The same type of chart is obtained at other high temperatures. Such charts also explain the formation of $\mathrm{Si}-\mathrm{C}$ covalent bonds by cross-linking of long chains $\mathrm{C}_{n} \mathrm{H}_{p} \mathrm{Si}_{m}$ and loss of hydrogen.

Figure 5 presents the evolution of the production of $\mathrm{SiH}_{n}$ radicals with $n=1-4$ during the pyrolysis of the HPCS at $3200 \mathrm{~K}$. There are large fluctuations since the radicals lose their hydrogen, but because the system is highly reactive, they also form bonds with the hydrogen radicals, giving rise 


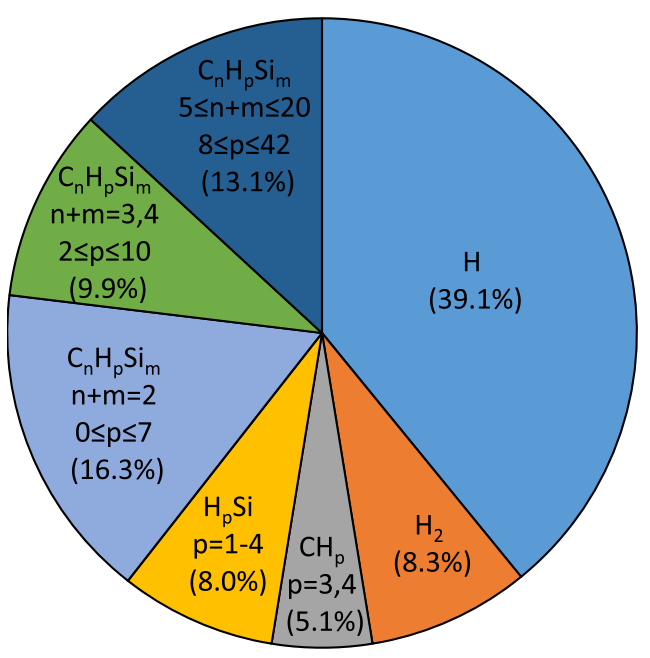

FIG. 4. The "pie chart" for the radicals and molecules produced during pyrolysis of HPCS polymer at $3600 \mathrm{~K}$.

to the fluctuations. Some clear trends can also be discerned. The number of $\mathrm{SiH}$ is always very small, followed by $\mathrm{SiH}_{2}$. Some of the two radicals are of course converted to $\mathrm{SiH}_{3}$ and $\mathrm{SiH}_{4}$ and some lose all of their hydrogen, leaving Si to form covalent bond with carbon. Similar trends were observed for $\mathrm{CH}_{n}(n=1-4)$ and, thus, are not shown.

Figure 6 presents the same as in Fig. 5, but at $4000 \mathrm{~K}$. Once again, the number of the $\mathrm{SiH}$ is small, but larger than what is produced at $3200 \mathrm{~K}$. The fluctuations in the number of $\mathrm{SiH}_{n}$ with $n=2-4$ are also larger than those at $3200 \mathrm{~K}$. Figure 7 presents the results for $\mathrm{CH}_{n} \mathrm{Si}$, with $n=1-6$, at $4000 \mathrm{~K}$. As expected, the number of CHSi is low, while after an initial "burst," the number of produced $\mathrm{CH}_{n} \mathrm{Si}$ with $n=2-4$ clearly decays with time, since they are decomposed at such a high temperature.

We also studied the kinetics of $\mathrm{H}_{2}$ formation. In Fig. 8, we show the raw data for the time-dependence of the number of $\mathrm{H}_{2}$ produced, $N(t)$, at $3000 \mathrm{~K}$, as well as their smoothed version. Also shown is the fit of the smoothed data to the functional form,

$$
N(t)=N_{f}-\left(N_{f}-N_{0}\right) \exp (-k t)
$$

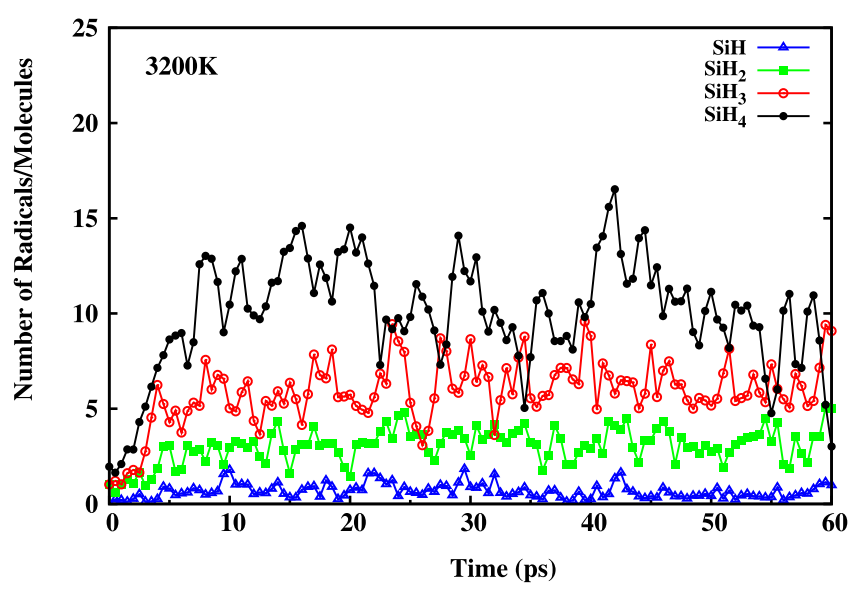

FIG. 5. Time-dependence of production of $\mathrm{SiH}_{n}$ during MD simulation in the $(N V T)$ ensemble at $3200 \mathrm{~K}$.

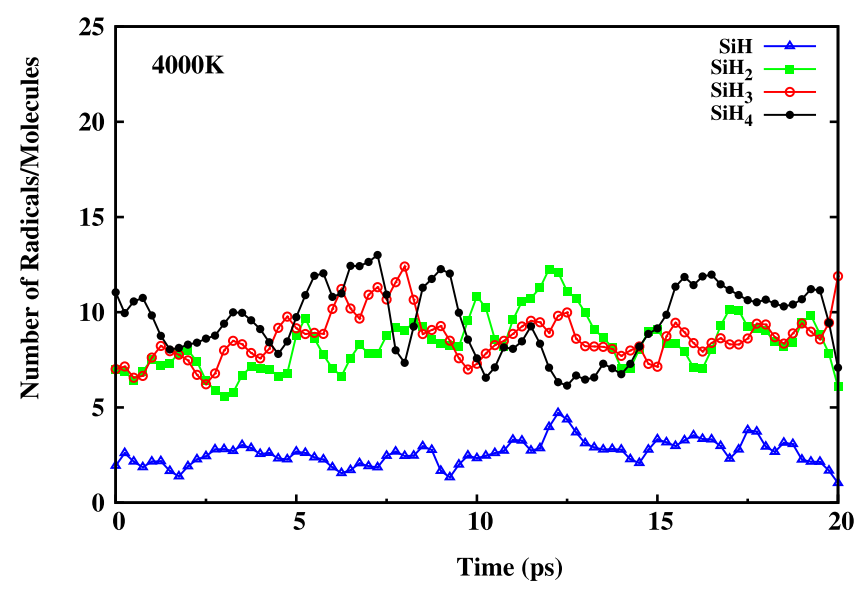

FIG. 6. Same as in Fig. 4, but at $4000 \mathrm{~K}$.

where $N_{0}$ and $N_{f}$ are the initial and final number of produced $\mathrm{H}_{2}$ in the simulation and $k$ is a kinetic constant in $\mathrm{ps}^{-1}$. Except for early times, the functional form provides a reasonable fit of the smoothed data. Note that the methodology of removing $\mathrm{H}$ radicals does not have any significant effect on the dynamics and the quality of the final products, which was confirmed by comparing with experimental data. Thus, Fig. 7 presents the general trends of $\mathrm{H}_{2}$ production.

\section{B. Properties of the SiC film}

The density of $\mathrm{SiC}$ ceramic resulting from the pyrolysis of the HPCS has been reported ${ }^{38}$ to be $2.2 \mathrm{~g} / \mathrm{cm}^{3}$. The final structure from the RMD and then MD simulations also has the same density.

The three major $\mathrm{SiC}$ polytypes are ${ }^{1,2}(\beta) 3 \mathrm{C}-\mathrm{SiC},(\alpha) 6 \mathrm{H}-$ $\mathrm{SiC}$, and $4 \mathrm{H}-\mathrm{SiC}$. The Crystal Builder module in Cerius $2^{39}$ and its associated unit cell parameters ${ }^{40}$ were used to construct the $\mathrm{SiC}$ crystals. For each crystalline form, the quantum energies were computed in order to describe both expansion and compression. Figure 9 compares the ReaxFF results with those obtained by the DFT. Optimization of $\beta$-SiC crystal with ReaxFF yielded a density of $3.16 \mathrm{~g} / \mathrm{cm}^{3}$ at $300 \mathrm{~K}$, compared with the experimental value, $3.21 \mathrm{~g} / \mathrm{cm}^{3}$.

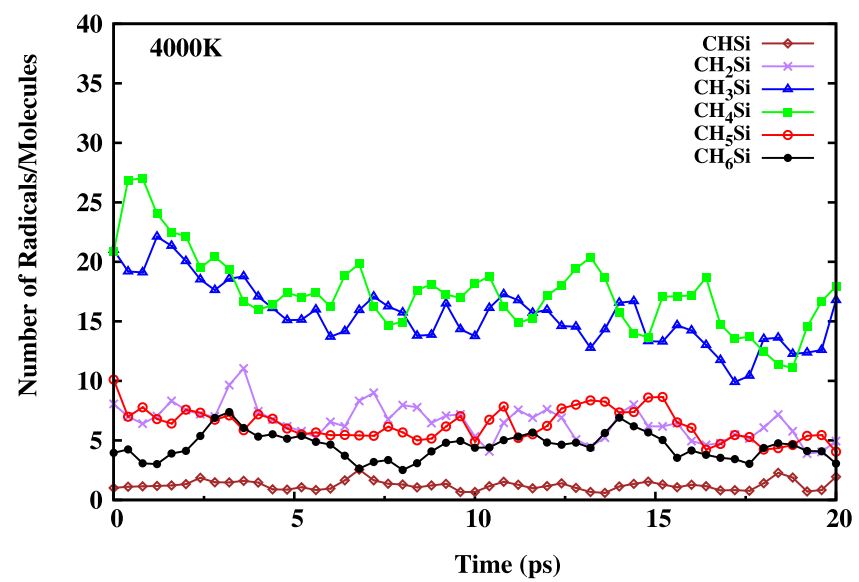

FIG. 7. Time-dependence of production of $\mathrm{CH}_{n} \mathrm{Si}$ during MD simulation in the $(N V T)$ ensemble at $4000 \mathrm{~K}$. 

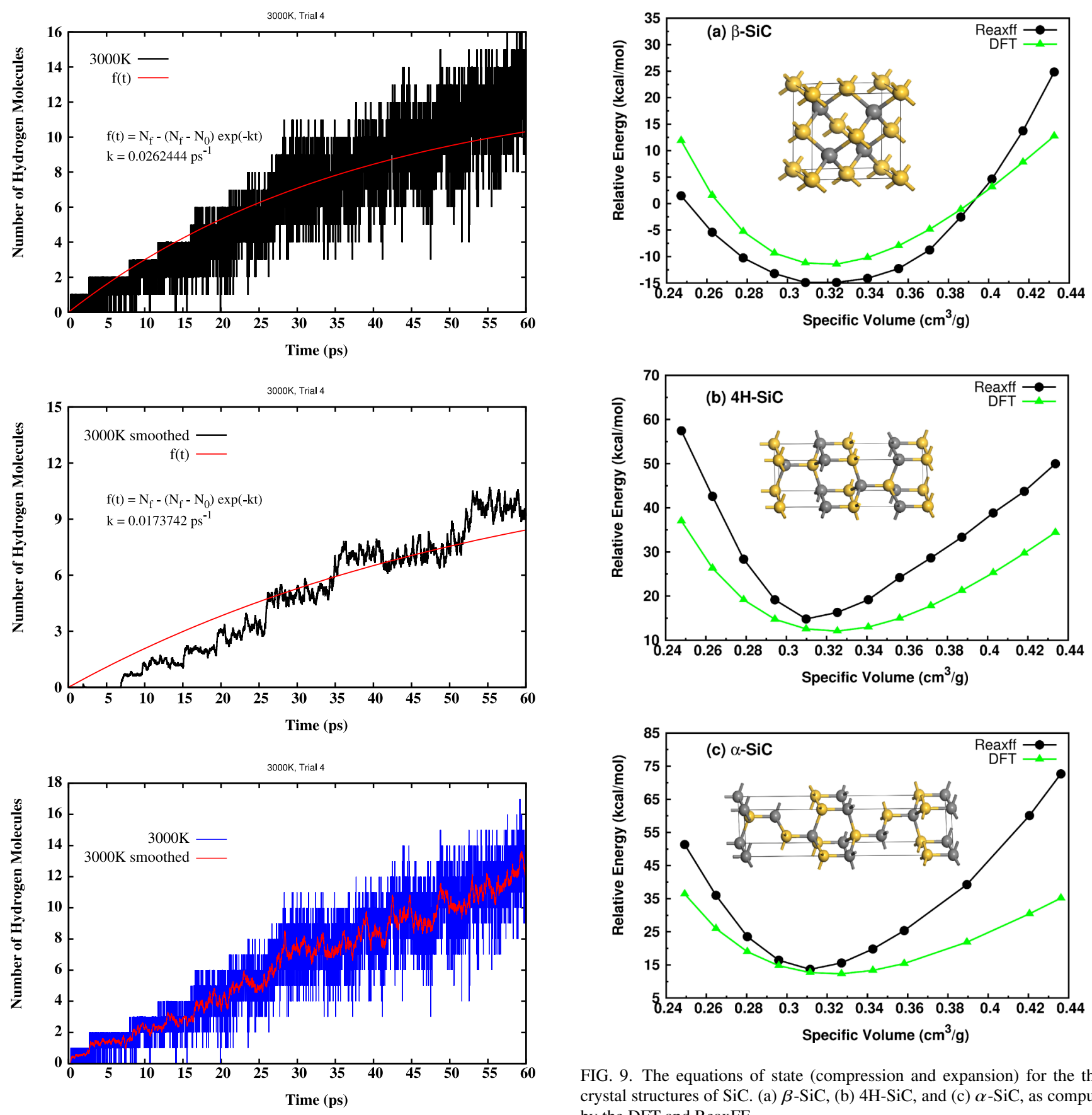

FIG. 8. Temperature-dependence of the rate of production of $\mathrm{H}_{2}$ according to both the original and smoothed data (top), the fitted curve against the original (middle), and against the smoothed data (bottom). The results are for $3000 \mathrm{~K}$.

Figure 9 indicates, for large expansions, significant difference between the energies computed by ReaxFF and the DFT. This does not, however, cause a problem for the phenomenon of interest to us in this paper because the most relevant and physically interesting parts are the equilibrium volumes from which the relative phase stabilities are deduced. We also point out that the important point in using ReaxFF is to enable chemical reactions to proceed with appropriate energy barriers. Thus, ReaxFF uses a bond energy-to-bond order-to bond distance relation that captures double and single bonds, as well as lower-order bonds during the reactions. As a result, the compressibility curves computed by ReaxFF are generally

FIG. 9. The equations of state (compression and expansion) for the three crystal structures of SiC. (a) $\beta-\mathrm{SiC}$, (b) $4 \mathrm{H}-\mathrm{SiC}$, and (c) $\alpha-\mathrm{SiC}$, as computed by the DFT and ReaxFF.

not as accurate as one would like them to be. For covalent systems, calculations of accurate second-order properties are best carried out by using ReaxFF to obtain the structure, and then one should use a nonreactive FF to analyze the distortions near the equilibrium structure.

We also computed ${ }^{41}$ the radial distribution function $g(r)$ of the final $\mathrm{SiC}$ film at $300 \mathrm{~K}$ and compared it with the data $^{42}$ at $300 \mathrm{~K}$. Generally speaking, the agreement between the computed $g(r)$ and the data is good. In particular, both the data and the atomistic model of amorphous $\mathrm{SiC}$ indicate the existence of some $\mathrm{Si}-\mathrm{Si}$ and $\mathrm{C}-\mathrm{C}$ in the material. As we reported previously, ${ }^{41}$ there are only some small differences between the computed and experimental $g(r)$. The reason is, in order to observe the reactions in computational time scale, we accelerated the reactive dynamic simulation, 
as described earlier. This meant using higher heating rate and higher pyrolysis temperatures, when compared with the experiment. The difference has some minor effect on the quality of the output $\mathrm{SiC}$ and, therefore, some minor differences in the radial distribution function. The structure of the amorphous $\mathrm{SiC}$ film was further validated by computing its x-ray diffraction pattern. Comparison ${ }^{41}$ with the data ${ }^{43}$ also indicated good agreement between the computed and measured x-ray diffraction patterns.

Study of flow and transport of fluids in confined media, and in particular in nanoporous media, is currently of fundamental and practical interest. The reason is threefold. First, the energy dissipation caused by friction in confined fluid can change the chemistry of the process and, in addition to forming new components, phase transitions as well as drastic changes in the fluid's static and dynamical properties also occur, which are phenomena of fundamental importance that can be very different from those under the bulk conditions. Second, it is clearly of practical interest to understand the mechanism of transport in the pore space of nanoporous materials. Third, the morphology of such materials is characterized and better understood by studying transport (and adsorption) in their pore space.

One particular class of nanoporous materials of interest to us contains pores with an average size of about a few $\AA$. Due to such exceedingly small pore sizes that are comparable with those of the fluids typically passing through them, the main resistance to the flow and transport in nanoporous material is due to the nano- and mesopores and, therefore, the molecular interactions between the gases' molecules, as well as between them and the pores' walls, are important and cannot be ignored. Hence, one must utilize atomistic modeling and simulation to study the transport processes that take place in the pore space of such materials. We have been fabricating various types of nanoporous materials for use as membranes, such as carbon molecular-sieve membranes ${ }^{44}$ nanotube-polymer composites, ${ }^{27}$ and $\mathrm{SiC}$ nanoporous membranes. ${ }^{3}$

Thus, having established the accuracy of ReaxFF for simulating the pyrolysis of HPCS and the atomistic model of amorphous $\mathrm{SiC}$ film, we now turn our attention to the properties of the amorphous $\mathrm{SiC}$ film that is produced by the pyrolysis process, after the system is cooled back to room temperature. Amorphous $\mathrm{SiC}$ films have been used by $\mathrm{us}^{3}$ as the membrane layer for separation of gaseous mixtures into their constituents. Thus, we are interested in the free-volume distribution of the films and the effective diffusivities of various gases in the $\mathrm{SiC}$ films.

(1) The force field: We computed the self-diffusivities of three gases in the $\mathrm{SiC}$ film, namely, $\mathrm{H}_{2}, \mathrm{CO}_{2}$, and $\mathrm{CH}_{4}$, because the $\mathrm{SiC}$ nanoporous films are used for separation of mixtures of the three gases. ${ }^{3}$ To do so, one must specify the interaction potentials between the gases and the $\mathrm{SiC}$ film. For this purpose, we used the universal force field ${ }^{45}$ (UFF). The parameters of the UFF have been estimated according to general rules based only on the atomic element, its connectivity, and hybridization. The total energy $E$ according to the UFF is given by

$$
E=E_{S}+E_{\theta}+E_{\phi}+E_{\omega}+E_{\mathrm{vdWaals}}+E_{\mathrm{ES}},
$$

with

$$
\begin{gathered}
E_{s}=\frac{1}{2} S_{i j}\left(\ell-\ell_{i j}\right)^{2}, \\
E_{\theta}=T_{i j k} \sum_{n=1}^{m} C_{n} \cos (n \theta), \\
E_{\phi}=P_{i j k l} \sum_{n=1}^{m} C_{n} \cos \left(n \phi_{i j k l}\right), \\
E_{\omega}=G_{i j k l}\left[C_{0}+C_{1} \cos \omega_{i j k l}+C_{2} \cos \left(2 \omega_{i j k l}\right)\right], \\
E_{\mathrm{vdWaals}}=V_{i j}\left[\left(\frac{r_{i j}}{r}\right)^{12}-2\left(\frac{r_{i j}}{r}\right)^{6}\right], \\
E_{\mathrm{ES}}=332.0637 \frac{q_{i} q_{j}}{\epsilon r_{i j}} .
\end{gathered}
$$

Here, $E_{s}$ is the energy associated with bond stretching, with $\ell_{i j}$ being the equilibrium or natural bond length, $\ell$ being the actual length at any time during the simulation, and $S_{i j}$ being a stretching-force constant. $E_{\theta}$ represents the energy associated with the changes in the bonds' angles, where the coefficients $C_{n}$ are chosen to satisfy the appropriate, physically justified boundary conditions where the function has a minimum at an equilibrium bond angle $\theta_{0}, \theta$ is the angle at any given time during the simulation, and $T_{i j k}$ is the corresponding force constant. The contribution of the torsional forces is represented by $E_{\phi}$, with $P_{i j k l}$ being a force constant. Values of $P_{i j k l}$ and the coefficients $C_{n}$ are determined by the rotational barrier $V_{\phi}$, the periodicity of the potential, and the equilibrium angle. For a given central $j-k$ bond, all torsions about this bond are considered, with each torsional barrier being divided by the number of torsions present about the bond. $E_{\omega}$ represents the energy associated with the inversion, with $G_{i j k l}$ being a force constant and $\omega_{i j k l}$ being the angle between the $i l$ axis and the $i j k$ plane. $E_{\mathrm{vdWaals}}$ is the van der Waals type potential represented by a LJ 6-12 type potential for the nonbond interactions, with $V_{i j}$ being the well depth and $r_{i j}$ being the van der Waals bond length. The general $r_{i j}$ and $V_{i j}$ are obtained from the homonuclear parameters through the use of combination rules

$$
\begin{aligned}
& r_{i j}=\left(r_{i} r_{j}\right)^{1 / 2}, \\
& V_{i j}=\left(V_{i} V_{i}\right)^{1 / 2} .
\end{aligned}
$$

Finally, $E_{\mathrm{ES}}$ represents the energy associated with the electrostatic interactions, where $q_{i}$ is the atomic charge. In the simulations, the potential energy for the nonbonded interactions was cut off at $6 \AA$. We used the Ewald summation technique and the multiple expansion method ${ }^{28,46}$ in order to account for the electrostatic interactions. All the parameters of the UFF are given in the original reference. ${ }^{45}$

(2) Computing the accessible free volume and solubility: The free-volume (FV) distribution is important to transport of the gases through the $\mathrm{SiC}$ films. To compute the FV distribution, MD simulations in the (NPT) ensemble were carried out. Twenty configurations of the SiC film structures were taken from the simulation trajectories after every $50 \mathrm{fs}$. The accessible FVs were then computed using the following method using a hard-sphere probe. First, the cubic simulation cell was partitioned into a three-dimensional mesh of 
$100 \times 100 \times 100$ elementary cells. Then, a hard sphere of a given diameter was inserted as the probe at the center of each elementary cell, and the distance to the nearest atoms of the material was computed. If the distance turned out to be larger than the sum of the van der Waals radii of the penetrant molecule and the material's atom, the elementary cell was considered as contributing to the accessible free volume. The cavity volume was then computed using a Voronoi tessellation of the space based on the algorithm of Tanemura et al. ${ }^{47}$ The vectors connecting the atoms' centers in the system were perpendicularly bisected and a large number of intersecting planes were generated. The polyhedra associated with the atoms were then constructed using the algorithm. As a Voronoi polyhedron around an atom identifies its own available space, it can be related to the void volume of the $\mathrm{SiC}$ film, which was then used to study the evolution of the free volume. ${ }^{48}$

(3) Computing the self-diffusivity of the gases: To compute the self-diffusivity of $\mathrm{H}_{2}, \mathrm{CH}_{4}$, and $\mathrm{CO}_{2}$ in the $\mathrm{SiC}$ model, 10 molecules of each gas were inserted in the $\mathrm{SiC}$ film separately. For convenience, we use $\mathrm{MH}_{2}, \mathrm{MCH}_{4}$, and $\mathrm{MCO}_{2}$ to denote the $\mathrm{SiC}$ material that contains $\mathrm{H}_{2}, \mathrm{CH}_{4}$, and $\mathrm{CO}_{2}$, respectively. In each case, the system was constructed by adding one gas molecule at a time, in a stepwise fashion, into the $\mathrm{SiC}$ model. The molecules were randomly inserted in the free space of the $\mathrm{SiC}$ film and any physically unacceptable contact and overlap between the gaseous molecules and the atoms of the $\mathrm{SiC}$ model was avoided. After the insertion of every gas molecule, the total energy of the system was minimized using the conjugategradient algorithm. The process was followed until the desired number of gas molecules in the $\mathrm{SiC}$ flim was reached. To suppress the surface effects and the small size of the system, the periodic boundary conditions were used.

After generating the $\mathrm{SiC}$ film-containing systems, the energy of the materials was first minimized until it achieved its true minimum. To further equilibrate the structures after energy minimization, MD simulations were carried out in the $(N V T)$ ensemble for $20 \mathrm{ps}$ at $300 \mathrm{~K}$. Then, another series of MD simulations was carried out in the (NPT) ensemble for several $\mathrm{ns}$ at $1 \mathrm{~atm}$ and $300 \mathrm{~K}$. The time step was $1 \mathrm{fs}$. The pressure was controlled by the Andersen method, ${ }^{31}$ while the temperature was held fixed using the Nosé-Hoover thermostat ${ }^{32}$ (see the earlier discussions).

The cell length and density of the $\mathrm{SiC}$ films were about $21.4 \AA$ and $2.2 \mathrm{~g} / \mathrm{cm}^{3}$, respectively. The cell lengths and densities, after energy minimization and relaxation, were about $23.7 \AA$ and $2.22 \mathrm{~g} / \mathrm{cm}^{3}$ for $\mathrm{MH}_{2}, 24.2 \AA$ and $2.25 \mathrm{~g} / \mathrm{cm}^{3}$ for $\mathrm{MCH}_{4}$, and $23.6 \AA$ and $2.29 \mathrm{~g} / \mathrm{cm}^{3}$ for $\mathrm{MCO}_{2}$. Given the void space in the pure (without any gas) $\mathrm{SiC}$ film (see below), their densities appear reasonable, considering the size of the cells and the mass of the gases.

The self-diffusivity of $\mathrm{H}_{2}, \mathrm{CO}_{2}$, and $\mathrm{CH}_{4}$ in the $\mathrm{SiC}$ film were estimated based on the mean-square displacements of the gas molecules using the Einstein relation,

$$
D=\frac{1}{6} \lim _{t \rightarrow \infty} \frac{d}{d t} \sum_{n=1}^{N}\left\langle|R(t)-R(0)|^{2}\right\rangle,
$$

where $D$ donates the self-diffusion coefficient and $R(t)$ is the Cartesian position vector of a gas molecule at time $t$.

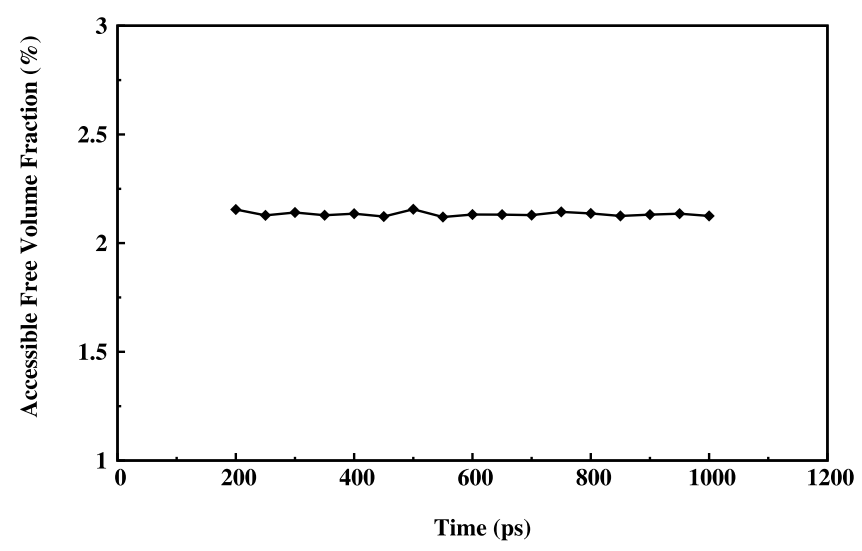

FIG. 10. Time-dependence of the accessible free volume fraction with a probe diameter of $2.5 \AA$.

The $\langle\cdots\rangle$ indicates averages over all the gas molecules and over all possible time origins for the motion of the molecules. The limiting slope of the mean-square displacement as a function of time is then used to evaluate the self-diffusion coefficient of a molecule undergoing random Brownian motion in three dimensions.

(4) Accessible free volume: The time dependence of the FV fractions $f_{v}$ for a probe of size $\sigma=2.5 \AA$, averaged over 20 configurations taken from the MD simulation in the (NPT) ensemble, is shown in Fig. 10, indicating that the fluctuations of $f_{v}$ were very small. In general, the characteristic times in the $\mathrm{SiC}$ model are so long that the accessible free volumes undergo very small fluctuations. Fluctuations of the accessible FVs in the $\mathrm{MCH}_{4}, \mathrm{MCO}_{2}$, and $\mathrm{MH}_{2}$ are somewhat larger than those in the pure $\mathrm{SiC}$ model, which is due to the presence of the gases and the fluctuations that they induce in the FV of the pores of the $\mathrm{SiC}$ film. Such features indicate that the atomistic models that we have generated for the $\mathrm{SiC}$ model and its gaseous mixtures should be quite reasonable.

Figure 11 presents the $\mathrm{FV}$ fraction $f_{v}$ as a function of the probe diameter, represented by its LJ size parameter $\sigma$, for the pure $\mathrm{SiC}$ film and $\mathrm{MCH}_{4}, \mathrm{MCO}_{2}$, and $\mathrm{MH}_{2}$ systems. In all the cases, the $f_{v}$ decrease rapidly as the probe diameter increases, and are less than $1 \%$ when the probe diameter reaches $5 \AA$. This indicates that the insertion of the gases in the $\mathrm{SiC}$ film

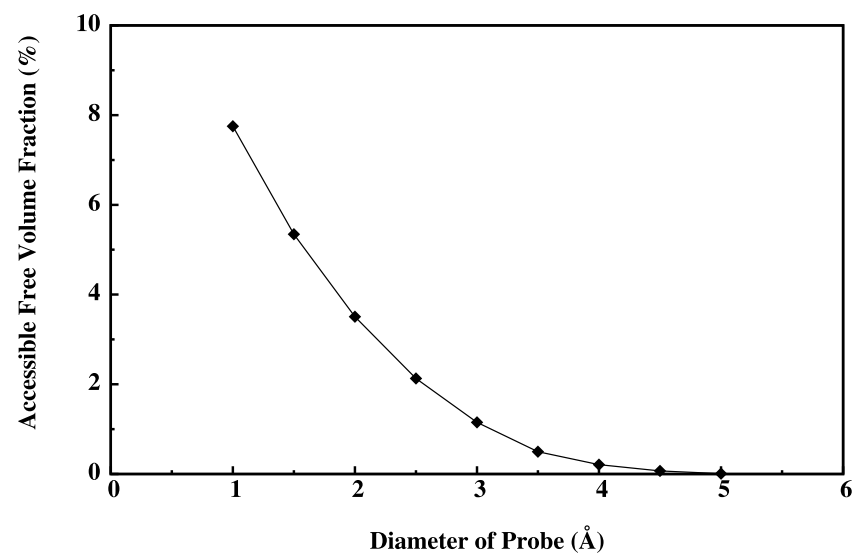

FIG. 11. The fraction of the free volume of amorphous $\mathrm{SiC}$ as a function of the probe size. 
does not change much the percentage and shape of the larger pores that the gases can diffuse into. There is, however, a difference in the values of $f_{v}$ for small probes, which is due to the repulsive interactions between the gaseous molecules and the $\mathrm{SiC}$ atoms and the fluctuations that such interactions induce in the material.

As described earlier, the Voronoi tessellation method was utilized to compute the distribution of the cavity sizes (volumes) for the unit cells of the $\mathrm{SiC}$ model, taking all the atoms into account. Figure 12 presents the resulting cavity volume distributions at three different times. They indicate that the distributions do not vary much with time, hence demonstrating the stability of the entire system. It is worth noting that there is a small but significant fraction of large cavity volumes. Considering the size and the volume of the gaseous molecules, the entire range of the cavity volumes
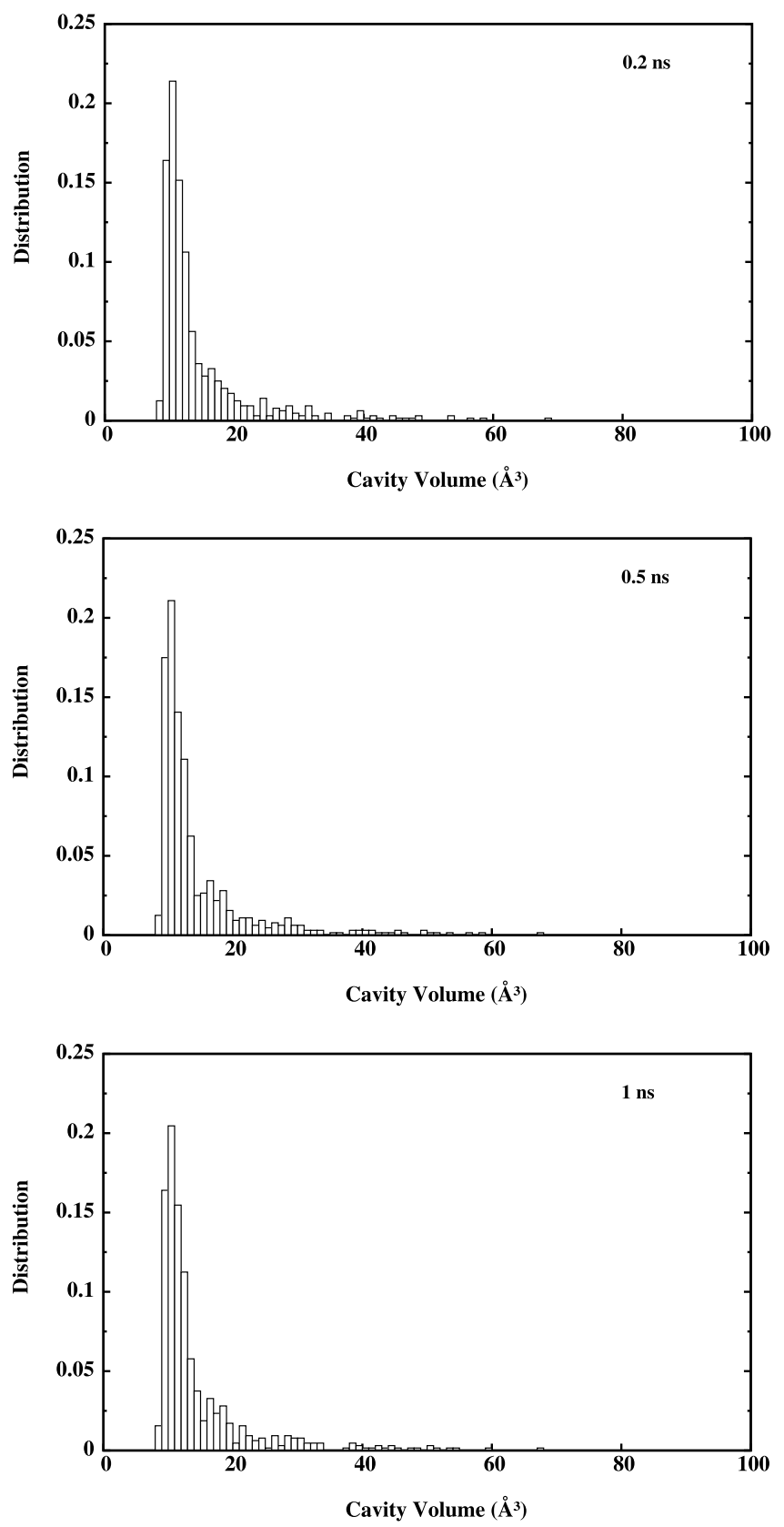

FIG. 12. The distribution of the free volumes at three different times.
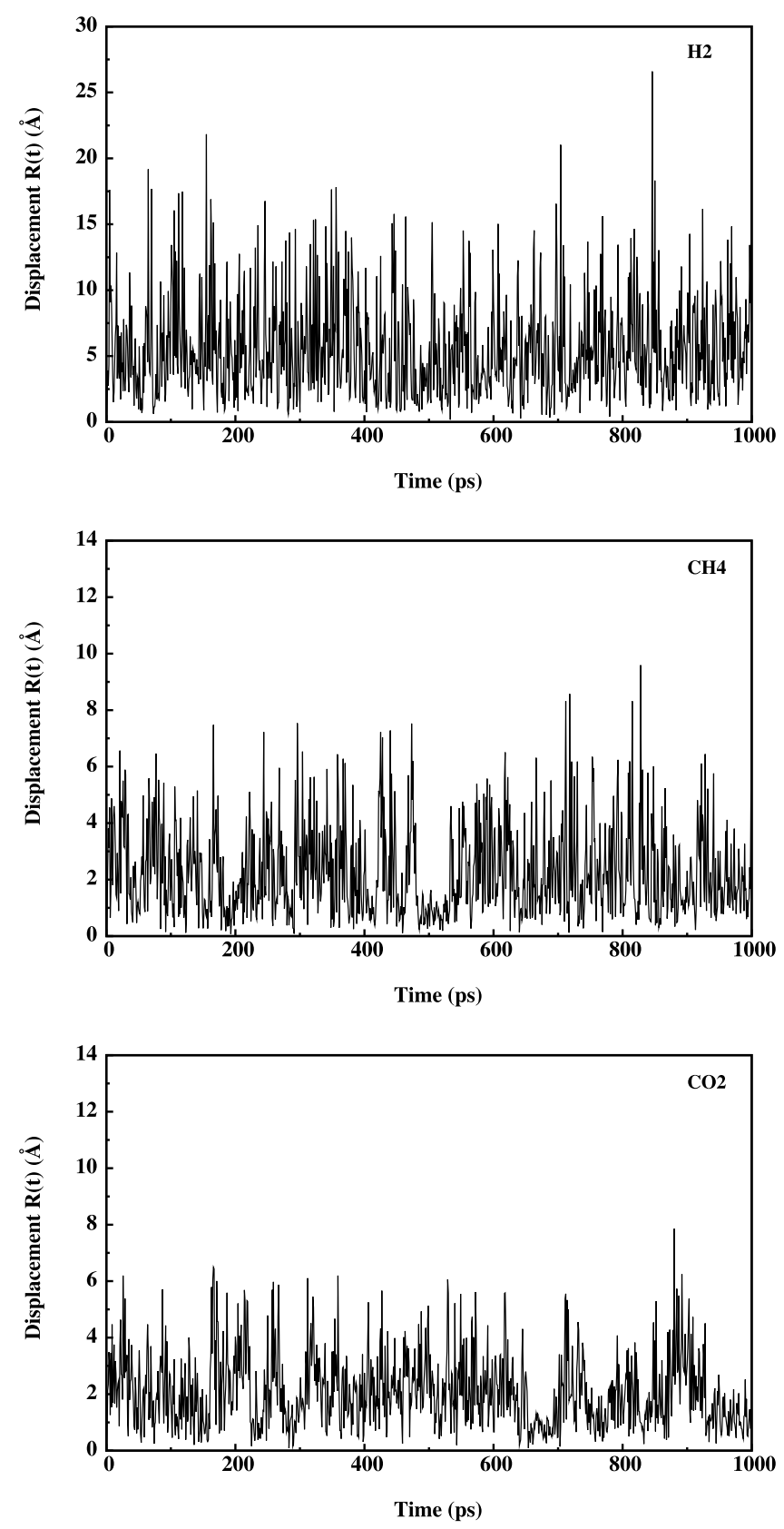

FIG. 13. Time-dependence of the displacements of the three gases relative to their last positions.

is responsible for gas permeation, diffusion, and separation, when used as a membrane or in other applications.

(5) The self-diffusivities: In amorphous $\mathrm{SiC}$, the accessible $\mathrm{FV}$ for the diffusion of small gases is distributed inhomogeneously throughout the system. Thus, the diffusion coefficients may vary significantly locally. That is, they may be different if computed for various parts of the amorphous SiC film. The dependence of the diffusivities on the local FV fraction may then be described by Doolittles' law, ${ }^{49}$

$$
D=A \exp \left(-\frac{B}{\eta_{\max }-\eta}\right),
$$

or a modification of it, ${ }^{50}$ where $\eta$ is the packing fraction of the material, with $\eta_{\max }$ being its maximum value, and $A$ and 

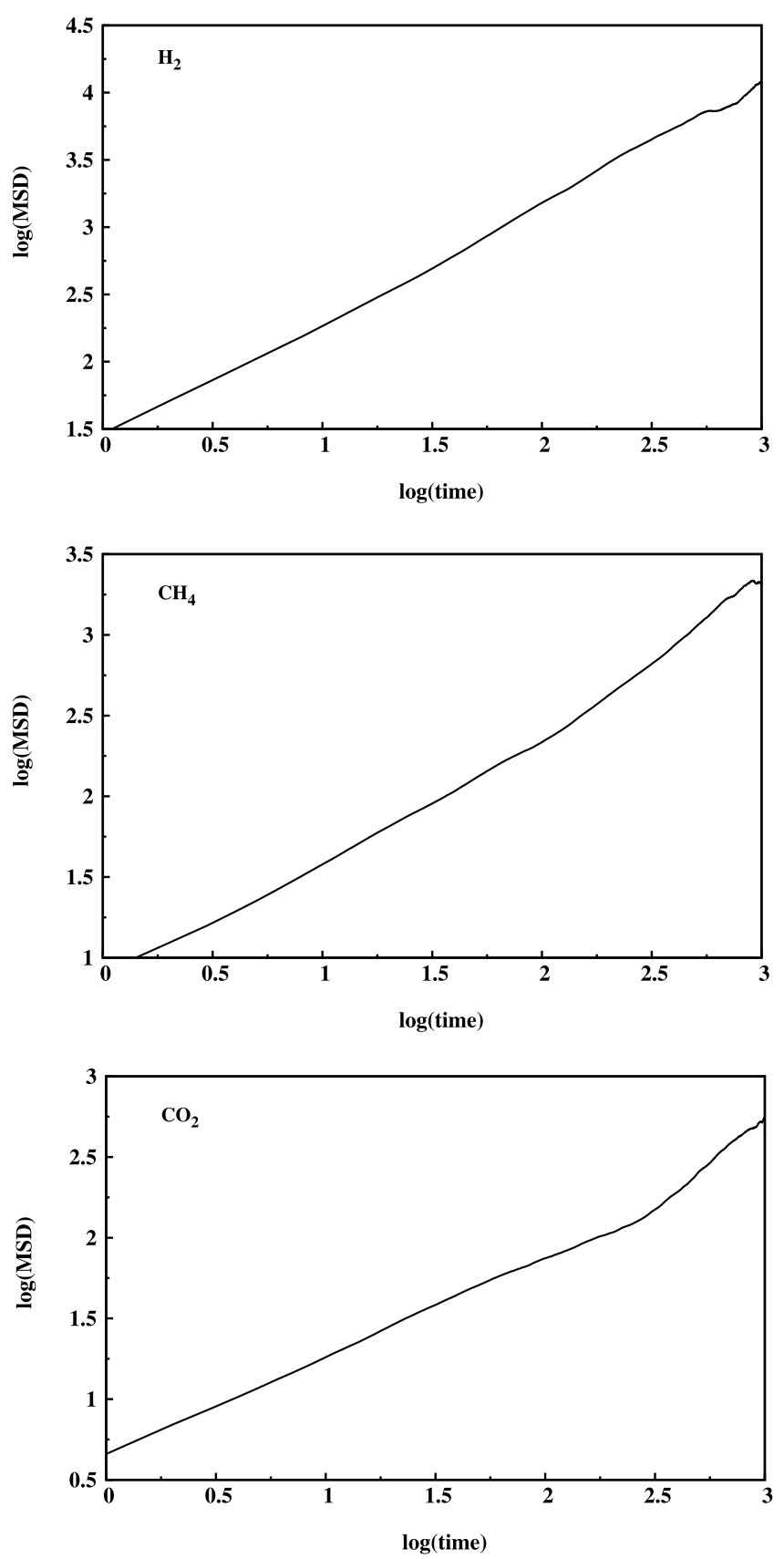

FIG. 14. Logarithmic plots of the mean-square displacements versus time of the three gases, computed in the $(N P T)$ ensemble at $300 \mathrm{~K}$.

$B$ being two constants. One may also consider the CohenTurnbull statistical mechanical theory according to which

$$
D=M \exp \left(-N \frac{v_{m}}{v_{a}}\right)
$$

where $M$ and $N$ are two constants, $v_{m}$ is the minimum free volume required for a diffusing molecule to escape its cage of neighboring atoms, and $v_{a}$ is the available free volume per volume of the occupying element. ${ }^{51}$ To decrease the degree of inhomogeneity for calculation of the self-diffusivities, 10 molecules of each gas were inserted in the $\mathrm{SiC}$ film at random positions, as described earlier.

The simulations indicated that $\mathrm{H}_{2}, \mathrm{CH}_{4}$, and $\mathrm{CO}_{2}$ take diffusion trajectories in the $\mathrm{SiC}$ material that are
TABLE II. The computed self-diffusivities $D$ of the three gases.

\begin{tabular}{ll}
\hline \hline Gas & $D \times 10^{4}\left(\mathrm{~cm}^{2} / \mathrm{s}\right)$ \\
\hline $\mathrm{H}_{2}$ & 1.81 \\
$\mathrm{CH}_{4}$ & 0.39 \\
$\mathrm{CO}_{2}$ & 0.09 \\
\hline
\end{tabular}

sample-spanning paths, indicating that the SiC film's pores are large enough for the gases to diffuse through. There is, however, an important difference between the three gases: $\mathrm{H}_{2}$ diffuses more efficiently than the other two gases. This implies that the amorphous $\mathrm{SiC}$ film is more favorable for diffusion and transport of $\mathrm{H}_{2}$ and, therefore, it is an effective material for its separation from the gaseous mixtures, in agreement with the experimental data and observations. ${ }^{3}$ The slowest molecule in the $\mathrm{SiC}$ film is $\mathrm{CO}_{2}$, which may be explained not only based on being a (relatively) heavy molecule but also due to the presence of the $\mathrm{C}$ atoms on the pores' surface. $\mathrm{CO}_{2}$ has some affinity for physical adsorption on the surface of pores that contain carbon, which slows down its motion.

To better understand the difference between the three gases, we show the time-dependence of their displacements $R(t)$ in Fig. 13. The displacement of $\mathrm{H}_{2}$ fluctuates between $1 \AA$ (essentially vibrations around its position) and $35 \AA$, while those of $\mathrm{CH}_{4}$ and $\mathrm{CO}_{2}$ fluctuate, respectively, between $1 \AA$ and $10 \AA$, and $1 \AA$ and $8 \AA$. These features are all consistent with the hopping mechanism that is often invoked to explain diffusion of small gas molecules in amorphous materials. According to the hopping mechanism, the gas molecules oscillate in a cavity until the tunnels between adjacent cavities are opened, which allow them to hop to the neighboring cavities, provided that they are not already occupied by other gas molecules. The magnitude of the oscillations and the frequency of the hops from one cavity to another depend on the material's density and morphology.

Figure 14 presents the logarithmic plots of the meansquare displacements of the three gases versus time at $273 \mathrm{~K}$, computed in the $(N P T)$ ensemble. In the Fickian regime of diffusion, a plot of $\log \left\langle R^{2}(t)\right\rangle$ versus time $\log t$ should eventually become a straight line with a slope of 1 . In all the cases, the slopes are indeed $\simeq 1$. The estimated diffusivities of

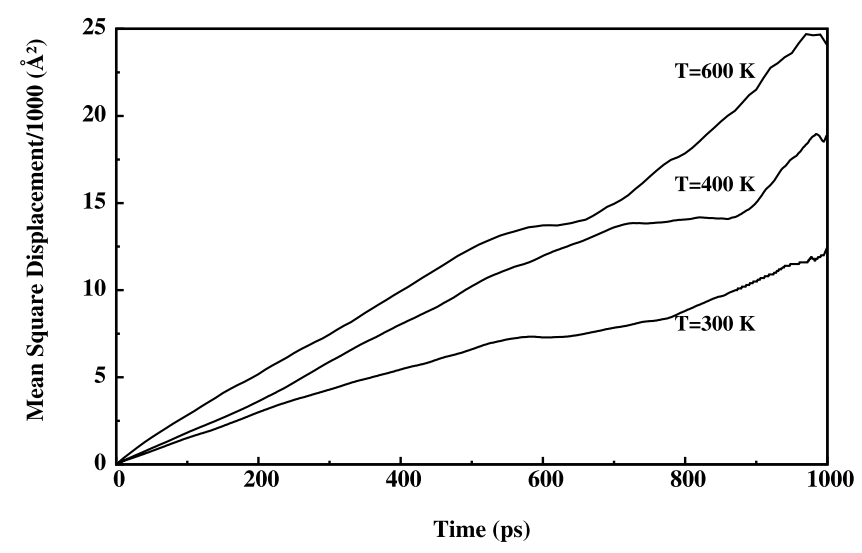

FIG. 15. Time- and temperature-dependence of the mean-square displacements of $\mathrm{H}_{2}$, computed in the (NPT) ensemble. 


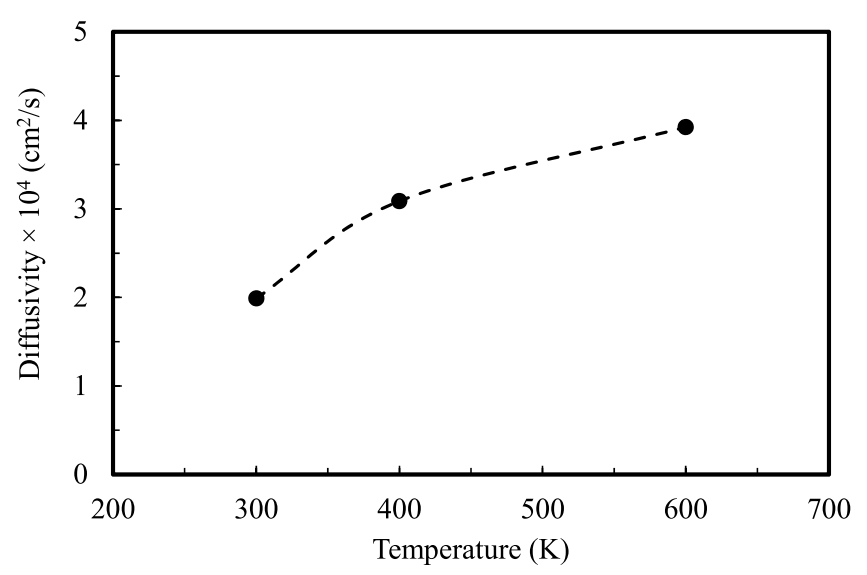

FIG. 16. Temperature-dependence of self-diffusivity of $\mathrm{H}_{2}$ in the model amorphous SiC film.

the three gases are listed in Table II. The estimates are all in the range of diffusivities of small gas molecules in amorphous materials.

Since separation of hydrogen from a gaseous mixture by $\mathrm{SiC}$ membranes is of prime interest to us, we computed its effective diffusivities at three temperatures that are encountered in practical applications of amorphous $\mathrm{SiC}$ as a membrane. The results for the mean-square displacements are shown in Fig. 15, while Fig. 16 presents temperaturedependence of the diffusivity of $\mathrm{H}_{2}$ in the amorphous $\mathrm{SiC}$ film.

\section{SUMMARY}

Based on the reactive force field ReaxFF, we described a first principles-based multiparadigm, multiscale strategy for simulating complex materials fabrication processes involving chemical reactions, which yields both the final material structure and other products of the processes. As an example, we simulated thermal decomposition of the polymer HPCS in order to generate an atomistic model of amorphous $\mathrm{SiC}$ film, a practice that is followed in the preparation of $\mathrm{SiC}$ nanoporous membranes. All the reaction products of the thermal decomposition of the polymer agree with the experimental data. ${ }^{33}$ Using extensive molecular dynamics simulations, we also calculated the structural and transport properties of the amorphous $\mathrm{SiC}$ film. Elsewhere, ${ }^{40}$ where we reported the results of our preliminary MD simulations, we showed that the computed radial distribution function and $\mathrm{x}$ ray diffraction pattern of the amorphous $\mathrm{SiC}$ film agree with the experimental data. Thus, the proposed methodology is a powerful tool for atomistic modeling of formation of complex materials that involve chemical reactions. The application of the method to $\mathrm{SiC}$ nanoporous membranes ${ }^{33}$ was recently reported elsewhere. ${ }^{52}$

\section{ACKNOWLEDGMENTS}

Work at USC was supported by the DOE and NSF. We thank Lianchi Liu for helpful discussions.

\footnotetext{
${ }^{1}$ A. W. Weimer, Carbide, Nitride, and Boride Materials: Synthesis and Processing (Springer, Berlin, 1997).
}

${ }^{2}$ M. S. Shur, S. L. Rumyantsev, and M. Levinshtein, SiC Materials and Devices (World Scientific, Singapore, 2006).

${ }^{3}$ V. Suwanmethanond, E. Goo, P. K. T. Liu, G. Johnston, M. Sahimi, and T. T. Tsotsis, Ind. Eng. Chem. Res. 39, 3264 (2000); R. Ciora, B. Fayyaz, P. K. T. Liu, V. Suwanmethanond, R. Mallada, M. Sahimi, and T. T. Tsotsis, Chem. Eng. Sci. 59, 4957 (2004); B. Elyassi, M. Sahimi, and T. T. Tsotsis, J. Membr. Sci. 288, 290 (2007); 316, 73 (2008); B. Elyassi, W. Deng, M. Sahimi, and T. T. Tsotsis, Ind. Eng. Chem. Res. 52, 10269 (2013).

${ }^{4}$ O. M. Yaghi, M. O'Keeffe, N. W. Ockwig, H. K. Chae, M. Eddaoudi, and J. Kim, Nature 423, 705 (2003); A. P. Cote, A. I. Benin, N. W. Ockwig, M. O'Keeffe, A. J. Matzger, and O. M. Yaghi, Science 310, 1166 (2005).

${ }^{5}$ B. Elyassi, T. W. Kim, M. Sahimi, and T. T. Tsotsis, Mater. Chem. Phys. 118, 259 (2009); K. Malek and M. Sahimi, J. Chem. Phys. 132, 014310 (2010); S. H. Barghi, T. T. Tsotsis, and M. Sahimi, Int. J. Hydrogen Energy 39, 21107 (2014).

${ }^{6}$ Q. Liu, H.-J. Wu, R. Lewis, G. E. Maciel, and L. V. Interrante, Chem. Mater. 11, 2038 (1999); L. V. Interrante, K. Moraes, L. MacDonald, and W. Sherwood, "Mechanical, thermochemical, and microstructural characterization of AHPCS-derived SiC," in Advanced SiC/SiC Ceramic Composites: Developments and Applications in Energy Systems, edited by A. Kohyama, M. Singh, H.-T. Lin, and Y. Katoh (John Wiley \& Sons, Inc., Hoboken, NJ, USA, 2006), Vol. 144, p. 123.

${ }^{7}$ K. Farah, F. Müller-Plathe, and M. C. Böhn, ChemPhysChem 13, 1127 (2012).

${ }^{8}$ A. C. T. van Duin, S. Dasgupta, F. Lorant, and W. A. Goddard, J. Phys. Chem. A 105, 9396 (2001); A. C. T. van Duin, A. Strachan, S. Stewman, Q. Zhang, X. Xu, and W. A. Goddard, ibid. 107, 3803 (2003); A. C. T. van Duin, Y. Zeiri, F. Dubnikova, R. Kosloff, and W. A. Goddard, J. Am. Chem. Soc. 127, 11053 (2005); S. Cheung, W. Q. Deng, A. C. T. van Duin, and W. A. Goddard, J. Phys. Chem. A 109, 851 (2005); K. D. Nielson, A. C. T. van Duin, J. Oxgaard, W. Q. Deng, and W. A. Goddard, ibid. 109, 493 (2005); L. Liu, A. Jaramillo-Botero, W. A. Goddard, and H. Sun, ibid. 116, 3918 (2012); K. Chenoweth, A. C. T. van Duin, P. Persson, M. J. Cheng, J. Oxgaard, and W. A. Goddard, J. Phys. Chem. C 112, 14645 (2008); A. Strachan, A. C. T. van Duin, D. Chakraborty, S. Dasgupta, and W. A. Goddard, Phys. Rev. Lett. 91, 098301 (2003).

${ }^{9}$ D. W. Brenner, Phys. Rev. B 42, 9458 (1990); D. W. Brenner, O. A. Shenderova, J. A. Harrison, S. J. Stuart, B. Ni, and S. B. Sinnott, J. Phys.: Condens. Matter 14, 783 (2002).

${ }^{10}$ M. R. Nyden and D. W. Noid, J. Phys. Chem. 95, 940 (1991).

${ }^{11}$ J. Tersoff, Phys. Rev. Lett. 56, 632 (1986); Phys. Rev. B 38, 9902 (1988); 37, 6991 (1988); 39, 5566 (1989).

${ }^{12}$ F. H. Stillinger and T. A. Webber, J. Phys. Chem. 91, 4899 (1987); J. Chem. Phys. 88, 5123 (1988); Phys. Rev. Lett. 62, 2144 (1989); H. Feil, J. Dieleman, and B. J. Garrison, J. Appl. Phys. 74, 1303 (1993); D. E. Hanson, J. D. Kress, and A. F. Voter, J. Chem. Phys. 110, 5983 (1999).

${ }^{13}$ K. Chenoweth, S. Cheung, A. C. T. van Duin, W. A. Goddard, and E. M. Kober, J. Am. Chem. Soc. 127, 7192 (2005).

${ }^{14}$ T. G. Desai, J. W. Lawson, and P. Keblinski, Polymer 52, 577 (2011).

${ }^{15}$ B. Saha and G. C. Schatz, J. Phys. Chem. B 116, 4684 (2012).

${ }^{16}$ Jaguar 5.5, Schrödinger, LLC, Portland, Oregan, 1991-2003.

${ }^{17}$ A. D. Becke, J. Chem. Phys. 98, 1372 (1993).

${ }^{18}$ R. Krishnan, J. S. Binkley, R. Seeger, and J. A. Pople, J. Chem. Phys. 72, 650 (1980); T. Clark, J. Chandrasekhar, G. W. Spitznagel, and P. V. R. Schleyer, J. Comput. Chem. 4, 294 (1983).

${ }^{19}$ P. C. Haharan and J. A. Pople, Theor. Chim. Acta 28, 213 (1973); M. M. Francle, W. J. Pietro, W. J. Hehre, J. S. Binkley, M. S. Gordon, D. J. DeFrees, and J. A. Pople, J. Chem. Phys. 77, 3654 (1982).

${ }^{20}$ P. Giannozzi et al., J. Phys.: Condens. Matter 21, 395502 (2009).

${ }^{21}$ J. P. Perdew, K. Burke, and M. Ernzerhof, Phys. Rev. Lett. 77, 3865 (1996).

${ }^{22}$ J. P. Perdew, A. Chevary, S. A. Vosko, K. A. Jackson, M. R. Pederson, D. J. Singh, and C. Fiolhais, Phys. Rev. B 46, 6671 (1992).

${ }^{23}$ H. J. Monkhorst and J. D. Pack, Phys. Rev. B 13, 5188 (1976).

${ }^{24}$ A. Jaramillo-Botero, S. Naserifar, and W. A. Goddard III, J. Chem. Theory Comput. 10, 1426 (2014).

${ }^{25}$ J. J. P. Stewart, J. Comput. Chem. 10, 209 (1989).

${ }^{26}$ D. N. Theodorou and U. W. Suter, Macromolecules 18, 1467 (1985); E. Tocci, D. Hofmann, D. Paul, N. Russo, and E. Drioli, Polymer 42, 521 (2001).

${ }^{27}$ M. M. Ostwal, T. T. Tsotsis, and M. Sahimi, Phys. Rev. E 79, 061801 (2009).

${ }^{28}$ A. R. Mehrabi and M. Sahimi, Phys. Rev. Lett. 82, 735 (1999).

${ }^{29}$ N. Kim, A. Harale, T. T. Tsotsis, and M. Sahimi, J. Chem. Phys. 127, 224701 (2008); A. R. Mehrabi and M. Sahimi, ibid. 128, 234503 (2008).

${ }^{30}$ D. Wolf, P. Keblinski, S. R. Phillpot, and J. Eggebrecht, J. Chem. Phys. 110, 8254 (1999). 
${ }^{31}$ H. C. Andersen, J. Chem. Phys. 72, 2384 (1980).

${ }^{32}$ S. Nosé, J. Chem. Phys. 81, 511 (1984); W. Hoover, Phys. Rev. A 31, 1695 (1985).

${ }^{33}$ L. V. Interrante, C. W. Whitmarsh, and W. Sherwood, MRS Proc. 346, 595 (1994).

${ }^{34}$ H. Q. Ly, R. Taylor, R. J. Day, and F. Heatley, J. Mater. Sci. 36, 4045 (2001).

${ }^{35}$ X. Tang, L. Zhang, H. Tu, H. Gu, and L. Chen, J. Mater. Sci. 45, 5749 (2010).

${ }^{36}$ P. Patnaik, Handbook of Inorganic Chemicals (McGraw-Hill, New York, 2002).

${ }^{37}$ S. Naserifar, L. Liu, W. A. Goddard, T. T. Tsotsis, and M. Sahimi, J. Phys. Chem. C 117, 3308 (2013).

${ }^{38}$ See http://www.starfiressystems.comfor Starfire Systems, Inc.; accessed 10 January 2013.

${ }^{39}$ Cerius2, version 4.0, Accelyrs, San Diego, 1999.

${ }^{40}$ Y. Goldberg, M. E. Levinshtein, and S. L. Rumyantsev, Properties of Advanced Semiconductor Materials: GaN, AIN, InN, BN, SiC, SiGe, edited by M. E. Levinshtein, S. L. Rumyantsev, and M. S. Shur (Wiley, New York, 2001), p. 93.

${ }^{41}$ S. Naserifar, W. A. Goddard, L. Liu, T. T. Tsotsis, and M. Sahimi, J. Phys. Chem. C 117, 3320 (2013).
${ }^{42}$ X.-Y. Tang, L. Zhang, H. B. Tu, H. Gu, and L. F. Chen, J. Mater. Sci. 45, 5749 (2010).

${ }^{43}$ M. Ishimaru, I.-T. Bae, Y. Hirotsu, S. Matsumura, and K. E. Sickafus, Phys. Rev. Lett. 89, 055502 (2002).

${ }^{44}$ M. G. Sedigh, W. J. Onstot, L. Xu, W. L. Peng, T. T. Tsotsis, and M. Sahimi, J. Phys. Chem. A 102, 8580 (1998); M. G. Sedigh, L. Xu, T. T. Tsotsis, and M. Sahimi, Ind. Eng. Chem. Res. 38, 3367 (1999); M. G. Sedigh, M. Jahangiri, P. K. T. Liu, M. Sahimi, and T. T. Tsotsis, AIChE J. 46, 2245 (2000).

${ }^{45}$ A. K. Rappe, A. J. Casewit, K. S. Colwell, W. A. Goddard, and W. M. Skiff, J. Am. Chem. Soc. 114, 10024 (1992).

${ }^{46}$ H.-Q. Ding, N. Karasawa, and W. A. Goddard, J. Chem. Phys. 97, 4309 (1992).

${ }^{47}$ M. Tanemura, T. Ogawa, and N. Ogita, J. Comput. Phys. 51, 191 (1983).

${ }^{48}$ S. Y. Lim, T. T. Tsotsis, and M. Sahimi, J. Chem. Phys. 119, 496 (2003); S. Y. Lim, M. Sahimi, T. T. Tsotsis, and N. Kim, Phys. Rev. E 76, 011810 (2007).

${ }^{49}$ A. K. Doolittle, J. Appl. Phys. 22, 1471 (1951).

${ }^{50}$ J. Budzien, J. D. McCoy, and D. B. Adolf, J. Chem. Phys. 119, 9269 (2003).

${ }^{51}$ M. H. Cohen and D. Turnbull, J. Chem. Phys. 31, 1164 (1959); D. Turnbull and M. H. Cohen, ibid. 34, 120 (1961).

${ }^{52}$ S. Naserifar, W. A. Goddard, T. T. Tsotsis, and M. Sahimi, J. Membr. Sci. 473, 85 (2015). 